\title{
Cervical cancer in low and middle-income countries (Review)
}

\author{
RODNEY HULL ${ }^{1}$, MZWANDILE MBELE ${ }^{1}$, TSHEPISO MAKHAFOLA ${ }^{1}$ \\ CHINDO HICKS ${ }^{2}$, SHAO-MING WANG ${ }^{3}$, RUI MANUEL REIS ${ }^{4}$, \\ RAVI MEHROTRA ${ }^{5}$, ZILUNGILE MKHIZE-KWITSHANA ${ }^{6}$, \\ GIBSON KIBIKI $^{7}$, DAVID O. BATES $^{8}$ and ZODWA DLAMINI
}

\begin{abstract}
${ }^{1}$ SA-MRC/UP Precision Prevention and Novel Drug Targets for HIV-Associated Cancers Extramural Unit, Pan African Cancer Research Institute, Faculty of Health Sciences, University of Pretoria, Hatfield 0028, South Africa; ${ }^{2}$ Bioinformatics and Genomics Centre, School of Medicine, Department of Genetics, Louisiana State University, New Orleans, LA 70112, USA; ${ }^{3}$ National Cancer Centre, Cancer Hospital, Chinese Academy of Medical Sciences and Peking Union Medical College, Beijing 100730, P.R. China; ${ }^{4}$ Molecular Oncology Research Centre, Barretos Cancer Hospital, Sao Paulo 14784-400, Brazil; ${ }^{5}$ Indian Council of Medical Research, New Delhi, Delhi 110029, India; ${ }^{6}$ School of Medicine, University of Kwazulu-Natal, Durban, Kwazulu-Natal 4013, South Africa; ${ }^{7}$ East African Health Research Commission, East African Community, Bujumbura, Bujumbura Mairie 350, Burundi; ${ }^{8}$ Queen's Medical Centre, University of Nottingham, Nottingham, Nottinghamshire NG7 2UH, UK
\end{abstract}

Received April 23, 2019; Accepted October 16, 2019

DOI: $10.3892 / 01.2020 .11754$

\begin{abstract}
Cervical cancer is a malignant tumour that occurs in the cervix and is classified into two histological types, adenocarcinoma and squamous cell carcinoma (SCC); SCC is more common and accounts for $70 \%$ of all cases. In 2018 there were $~ 569,000$ new cases of cervical cancer diagnosed worldwide and $\sim 311,000$ deaths were attributed to cervical cancer. Of these, between 84 and $90 \%$ occurred in low- and middle-income countries (LMICs) such as South Africa, India, China and Brazil. The most common cause of cervical cancer is persistent infection caused by the sexually transmitted human papilloma virus. Other factors that contribute to the incidence of cervical cancer include geography, traditional practices and beliefs, the screening levels, socioeconomic status, healthcare access, public awareness, use of oral contraceptives, smoking and co-infection with HIV. An estimated 11 million women from LMICs will be diagnosed with cervical cancer in the next 10-20 years. The aim of this review was to explore various types of genetic and epigenetic factors that influence the development, progression or suppression of cervical cancer.
\end{abstract}

Correspondence to: Professor Zodwa Dlamini, SA-MRC/UP Precision Prevention and Novel Drug Targets for HIV-Associated Cancers Extramural Unit, Pan African Cancer Research Institute, Faculty of Health Sciences, University of Pretoria, 1 Bophelo Road, Hatfield 0028, South Africa

E-mail: zodwa.Dlamini@up.ac.za

Key words: cervical cancer, South Africa, India, Brazil, Tanzania, miRNA

\section{Contents}

1. Introduction

2. Cervical cancer incidence in low- to middle-income countries

3. Factors that contribute to the development of cervical cancer

4. Prevention and diagnosis of cervical cancer

5. Conclusions

\section{Introduction}

Cervical cancer is a malignant tumour of the cervix that can be divided into two histological types, adenocarcinoma (AC) and squamous cell carcinoma (SCC) (1). SCC is more common and has an occurrence rate of $70 \%$ (2). AC originates from glandular cells that line the cervical canal (the endocervix), whereas SCC originates from squamous cells lining the outer part of the cervix that opens to the ectocervix. The region in which the squamous and the thin, flat glandular cells are located is termed the transformation zone, and the majority of tumours originate from this zone (3).

The most common cause for the occurrence of cervical cancer is a persisting infection with the sexually transmitted human papilloma virus (HPV) (4). HPV is accountable for 90-100\% of cervical cancer cases amongst women, especially those $<35$ years old (5). The types of HPV can be classified as either high-risk (HR) or low-risk in terms of their association with precancerous, benign or cancer lesions (6). HR HPV 16 and 18 subtypes are the most prevalent subtypes of HPV, which are responsible for $70 \%$ of cervical cancer cases $(1,4)$. In addition, previous studies have identified an association 
between the HPV 16 and 18 subtypes and malignant tumours of the penis, vulva and anus $(1,7)$.

Globally, cervical cancer is the fourth most commonly diagnosed cancer amongst women, and it is especially common in low- and middle-income countries (LMICs) such as South Africa (SA), India, China and Brazil (8-10). A total of $\sim 569,000$ new cases of cervical cancer and 311,000 deaths linked to cervical cancer were reported worldwide in $2018(1,8)$. In total, $84 \%$ of the new cases and between 87 and $90 \%$ of the deaths occur in LMICs $(1,8)$. However, HPV infections and associated malignancies are also common in regions of high socioeconomic status. In 2008, 80 million individuals were estimated to be infected with HPV in the USA (11). Despite this, thousands more women from LMICs die prematurely from cervical cancer compared with women from developed countries $(2,12)$.

The aim of the current review was to discuss the types of genetic and epigenetic factors as well as socio-economic factors that influence the occurrence, progression or suppression of cervical cancer. These factors may assist in identifying potential prognostic and diagnostic tools (e.g. biomarkers) for the treatment of cervical cancer.

\section{Cervical cancer incidence in low- to middle-income countries}

In 2010, Bruni et al (5) reported a 4-fold higher prevalence of cervical cancer in LMICs compared with that in developed countries. In countries ranked low in the Human Development Index, cervical cancer is ranked as the second most common type of cancer and the second highest cause of cancer-related mortality amongst women after breast cancer. In Africa, cervical cancer is the most commonly diagnosed type of cancer and the leading cause of cancer-related death among women (13). Table I and Fig. 1 (14-16) present data from the GLOBOCAN 2018 report (15) and show the rate of cervical cancer in LMICs compared with that in developed countries. In Sub-Saharan Africa, the highest incidence of cervical cancer since 2012 was observed in women aged between 15 and 44 years $(15,17,18)$.

Gonidia and Sartorius (18) used three mathematical models to predict the prevalence of HPV in Swaziland by applying age-specific cervical cancer incidence rates from GLOBOCAN 2012 to the Swazi female population in $2014(13,18,19)$. The results revealed that the published incidence rates were a gross underestimation of the actual number of cervical cancer cases (18). Another model was used to regress age-standardised cervical cancer incidence (20) in Sub-Saharan African countries against HR HPV prevalence among women with normal cervical cytology (21). The model estimated that, among women with normal cervical cytology, the age-standardised cervical cancer incidence rate was 62.6 per 100,000 women; the prevalence of HPV-HIV among women with normal cytology exhibited a higher estimated age-standardised incidence of 101.1 per 100,000 women (21). South Africa has the highest age-standardised incidence of cervical cancer globally, with 32 cases per 100,000 women (22), whereas Paraguay (a middle-income country) has the highest incidence (34.2 per 100,000 women) and a mortality rate of 15.7 per 100,000 women $(21,23)$. These results indicated that women infected with HIV may be at a higher risk of developing HPV infection, pre-invasive cervical disease and invasive cervical cancer (ICC) $(18,24,25)$. Currently, South Africa has the highest incidence of HIV infection worldwide, with 7.2 million cases in a population of 58 million (26); an estimated 13 million women are infected with HIV in sub-Saharan Africa $(25,27)$. The treatment of cervical cancer in women infected with HIV presents with great difficulties. For example HIV infection increases the likelihood of the patient having a persistent HPV infection resulting in cervical abnormalities and cervical cancer (7). A compromised immune system and increased risk of HPV infection lowers the number of individuals that have been successfully treated in this population (25). The cancer burden in developing countries such as Swaziland is increased due to late diagnosis, advanced stages of HIV and HPV infections when the cancer is diagnosed, lack or inaccessibility of treatment, lack of treatment facilities, and logistic and cultural obstacles to treatment (28), which result in poor prognosis (14).

These factors, which are common to the majority of developing countries, resulted in the identification of an association between cervical cancer and the level of development (i.e. the socioeconomic status) of a country and its individuals. Cervical cancer is significantly associated with the geographical area; the highest incidence rates are prevalent in low-income countries (10). The incidence in 2013 was $24 \%$ in sub-Saharan Africa, 21\% in Eastern Europe and 16\% in Latin America (29). A prevalence of $>30 \%$ was also reported in Eastern Africa and the Caribbean (30). Southern Africa has the highest prevalence of HIV (19.9\% out of a population of $66,401,000)$, and the second highest cervical cancer incidence $(18.4 \%$ out of a total population of 668,319 women with cancer) after Asia and the Pacific (53.1\%) (27). This suggested that Southern Africa might have a leading number of HIV-associated cervical cancer cases.

Countries representing specific areas. As previously stated, areas where cervical cancer is the leading cause of death amongst women include Sub-Saharan Africa, Melanesia (Western Pacific), South Central and South East Asia, the Caribbean and Latin America (31). In wealthier developed countries, it is recommended that screening for cervical cancer with the Papanicolaou (Pap) smear is initiated at 21 years and repeated every year until the patient is 65 years old (32). Pap smears should be performed in conjunction with HPV screening; if the test reveals no signs of cervical cancer but presence of HPV, genotyping of the HPV should be performed, which may either be followed by a colposcopy, or HPV and cytology must be repeated at a later stage (33). Table II presents the age-standardised rate (ASR) which is the number per 100,000 people diagnosed with cervical cancer in the four countries, which will be discussed below. These four LMICs (South Africa, Tanzania, India and Brazil) are also compared against China Despite its large number of new cervical cancer cases, cervical cancer only comprises $2.5 \%$ of all cancer cases (15).

South Africa. The United Nations defines South Africa as an upper middle-income country with unequal distribution of wealth and a high rate of poverty (34). The 2014 South African National Cancer Registry statistics (35) for cervical cancer 
Table I. Region-specific incidence and mortality ASRs for cancers of the cervix in 2018.

\begin{tabular}{lcc}
\hline Region & Incidence & Mortality \\
\hline Southern Africa & 43.1 & 20.0 \\
Eastern Africa & 40.1 & 30.0 \\
Western Africa & 29.6 & 23.0 \\
Melanesia & 27.7 & 19.0 \\
Middle Africa & 26.8 & 21.1 \\
South-Eastern Asia & 17.2 & 10.0 \\
Eastern Europe & 16.0 & 6.1 \\
Caribbean & 15.5 & 8.5 \\
South America & 15.2 & 7.1 \\
Micronesia/Polynesia & 14.2 & 6.3 \\
Central America & 13.0 & 7.0 \\
South Central Asia & 13.0 & 8.2 \\
Eastern Asia & 10.9 & 4.1 \\
Northern Europe & 9.5 & 2.1 \\
Southern Europe & 7.8 & 2.2 \\
Northern Africa & 7.2 & 5.1 \\
Western Europe & 6.8 & 2.1 \\
Northern America & 6.4 & 1.9 \\
Australia/New Zealand & 6.0 & 1.7 \\
West Asia & 4.1 & 2.5 \\
\hline
\end{tabular}

ASR per 100,000 women. Rates are shown in descending order of the world Age Standardised incidence Rate (ASR), The ASRs for incidence and mortality are given for each region (15). ASR, age-standardised rate.

cases and deaths reported that the number of new observed cases in South African women was 5,735 in 2014, accounting for $16.17 \%$ of all cancers diagnosed in South African women; the ASR was 22.56 per 100,000 women (35). Analysis of the ASR and new cases by ethnic group revealed that the black population was more affected than any other group (Table III). The 'white' and 'other' population groups, which includes those of mixed ancestry, had $<10 \%$ of the number of cases and an ASR $<50 \%$ compared with the black population. The Asian population had the lowest number of cases and the lowest ASR. This population group is also the most economically disadvantaged and has poor access to healthcare (36). Since South Africa has the highest infection rate of HIV and the largest anti-retroviral program in the world (37), it is important to consider the influence of these two factors on cervical cancer. The total levels of HIV-related cancers have decreased following the introduction of anti-retroviral therapy; despite this, the mortality due to Acquired Immune Deficiency Syndrome (AIDS)-related illnesses is still high and has contributed to a lower life expectancy in South Africa (38). HIV is associated with abnormal cervical cytology and higher levels of HPV or numerous HPV types (34). The high prevalence of HIV in South Africa was predicted to lead to a marked increase in the incidence of cervical cancer, as it is one of the AIDS-defining illnesses, but such an increase has not occurred. Initially, prior to the introduction of anti-retroviral
Table II. Cervical cancer statistics.

\begin{tabular}{lrccc}
\hline & & \multicolumn{3}{c}{ ASR per } \\
Country & $\begin{array}{c}\text { New } \\
\text { cases (no.) }\end{array}$ & $\begin{array}{c}\text { All } \\
\text { cancers }(\%)\end{array}$ & $\begin{array}{c}100,000 \\
\text { women }\end{array}$ & (Refs.) \\
\hline South Africa & 5,735 & 15.17 & 22.56 & $(31)$ \\
Brazil & 16,370 & 8.1 & 12.2 & $(32)$ \\
India & 96,922 & 17 & 14.7 & $(26)$ \\
Tanzania & 9,772 & 37,9 & 59.1 & $(26)$ \\
China & 106,430 & 2.5 & 10.7 & $(26)$ \\
\hline
\end{tabular}

ASR, age-standardised rate.

Table III. Cervical cancer statistics in different population groups in South Africa (35).

\begin{tabular}{lccc}
\hline Group & $\begin{array}{c}\text { New } \\
\text { cases (no.) }\end{array}$ & $\begin{array}{c}\text { All } \\
\text { cancers (\%) }\end{array}$ & $\begin{array}{c}\text { ASR per } \\
100,000 \text { women }\end{array}$ \\
\hline Asian & 81 & 6.89 & 9.98 \\
Black & 4,870 & 30.46 & 27.01 \\
White & 407 & 3.45 & 13.10 \\
Other & 340 & 8.36 & 13.72 \\
\hline
\end{tabular}

ASR, age-standardised rate.

treatment, this was due to women succumbing to HIV/AIDS before they could develop cervical cancer; following the introduction of retroviral therapy, a decrease in the rates of all AIDS-defining cancers affected the numbers of cervical cancer cases (36).

The screening policy for cervical cancer in South Africa was established in 2000 and involves three Pap smears per lifetime starting at 30 years of age and occurring at 10-year intervals. The smear is repeated after 12 months if any abnormality is observed. If the abnormality persists or if a high-grade lesion is identified, the patient is referred for a colposcopy (39).

HPV is common among young, sexually active individuals; the infection normally clears without treatment, but recurrence is also common. Persistent infection with HR HPV genotypes leads to precancerous lesions and ultimately cervical carcinoma (39). Due to the high prevalence of transient HPV infection in young women among certain population groups, the usefulness of HPV screening as a tool for identifying those at risk of cervical cancer is limited (34). One preventive strategy for HPV infection used in South Africa is the introduction of the HPV vaccine. In 2014, a national school-based program for the HPV bivalent vaccine was introduced in all public schools, targeting girls in grade 4 (aged $\geq 9$ years old) with a two-dose (6 months apart) schedule (40). Although a high vaccination rate was achieved in these school based programs, the effect on HPV infection rates is yet to be elucidated.

Tanzania. Cervical cancer accounts for $40 \%$ of all cancer cases diagnosed in women in East Africa, with the highest ASR 


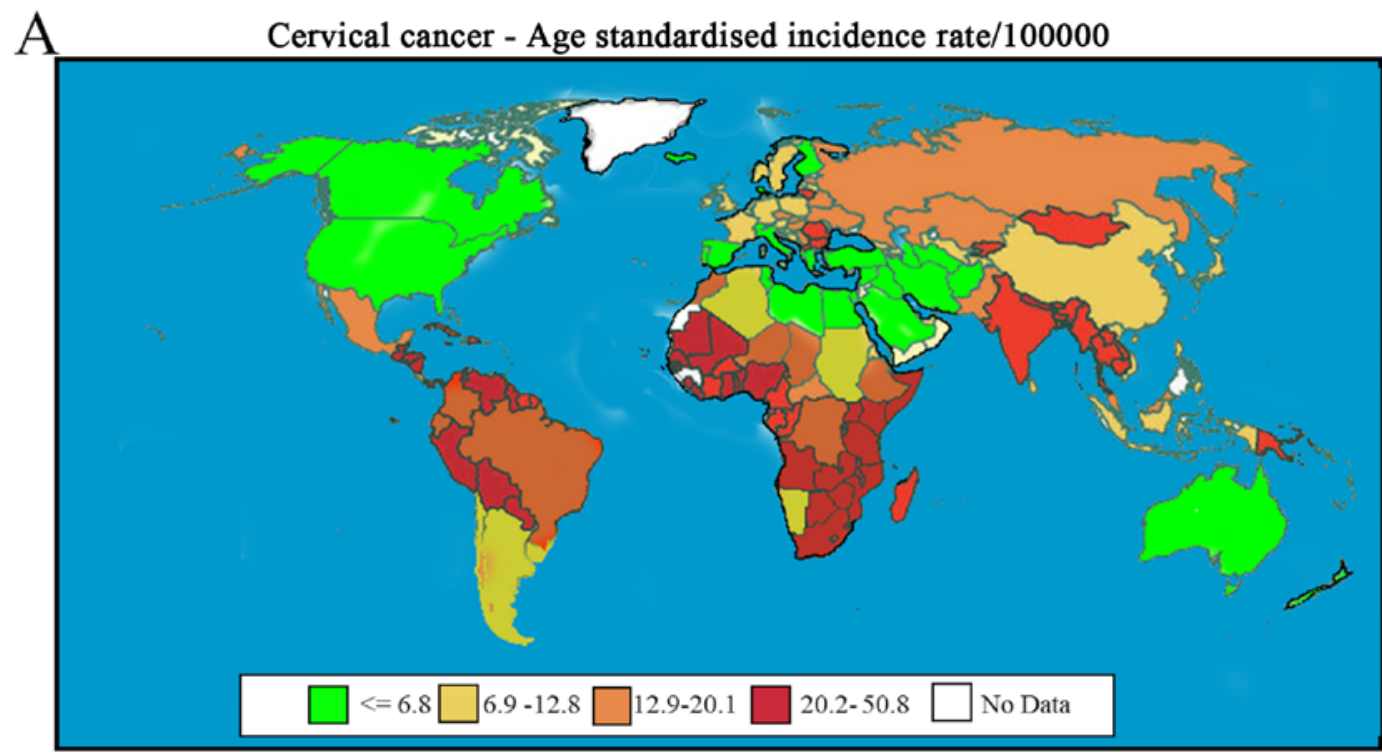

B

Age standardised rates (ASR) of cervical cancer based in countries based on economy

Developed countries

World average

Low income/

developing countries
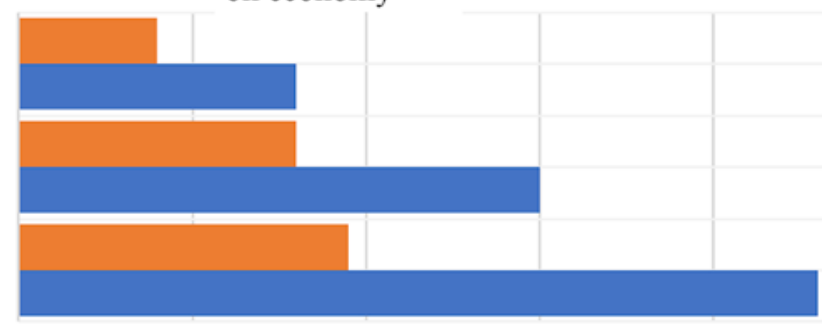

0

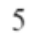

10

15

20

ASR/100000 people

C

Age standardised rates of cervical cancer in different regions
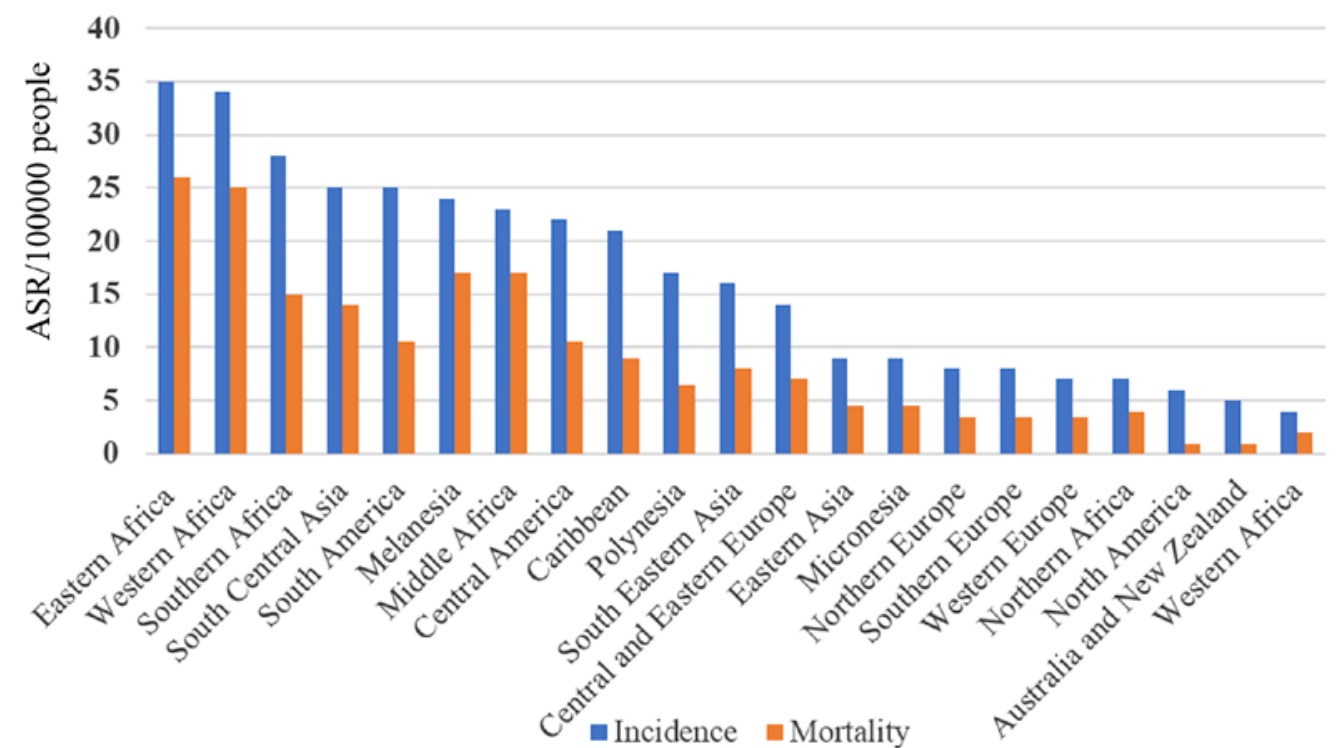

Figure 1. Incidence of cervical cancer. (A) Worldwide incidence by country. (B) The difference in incidence and mortality rates based on economic development compared with the global average. (C) Incidence and mortality rates based on geographic location.

(50.6 per 100,000 women) in Tanzania. Tanzania also ranks 13th on prevalence of HIV infection worldwide (15). Since women infected with HIV are at an increased risk of developing cervical cancer, it is important that they are screened early and often $(23,41)$. To combat cervical cancer, Tanzania has introduced a 'screen and treat' policy; the most common form of screening is visual inspection of the cervix with the naked eye following the application of acetic acid, abbreviated as visual inspection with acetic acid (VIA) (42). The acetic acid solution swabbed on the surface of the cervix (cervical epithelium) turns pre-cancerous 
lesions white (43). Following a positive diagnosis, the lesions are immediately treated by cryotherapy (41). Similarly to other low-income, developing countries, the rates of HPV infection are high in Tanzania; this has led to the Tanzanian Ministry of Health to initiate a school-based HPV vaccination program (44). Other factors that contribute to the high incidence of cervical cancer in Tanzania include; resource allocation (in term of distribution of trained personnel, funds and equipment in urban and rural areas nationwide), lack of resources to fulfil the needs of the entire population, sociocultural influence and a lack of political will (where leaders do not prioritise healthcare programmes and choose to divert funds and resources from screening and treatment programmes) (45). Sociocultural factors such as folklore and myths around cervical cancer screening influence the willingness of people to undergo screening (41).

India. In 2015, cervical cancer was the second most common cancer amongst women in India; an estimated 132,314 new cases were diagnosed and 73,337 patients succumbed to cervical cancer (46). Due to India's large population of 1.2 billion, this accounted for nearly one-fifth of all cervical cancer cases worldwide (47). It is difficult to determine an accurate ASR for India, as different cancer registries cover different areas, and ASRs vary between 9 and 40 per 100,000 women, depending on the region (47). India spends $0.9 \%$ of its gross domestic product (GDP) on healthcare, and no organised cervical cancer screening programs are available (48). Risk factors associated with cervical cancer in India include illiteracy, lack of toilets or running water inside the house, not washing genitals after sexual intercourse, age at first sexual intercourse $<15$ years, multiple lifetime sexual partners, widowhood and HPV (49). The prevalence of HR HPV in India ranges between 7 and 13\%, and HPV 16 and 18 are the most common types of HPV in India (50). This varies by region and is also possibly influenced by culture; however, unlike in developed countries, the number of young women diagnosed with HPV is not higher than that of older women (47), suggesting that the infection is equally distributed across all age groups.

HPV testing is cheap, objective and reproducible in rural areas in India (50). However, the use of HPV testing in a 'screen and treat strategy' can cause problems, as the majority of HPV infections in young women do not result in cervical cancer (47). HPV cytology-based cervical cancer screening is not possible for the entire population of India due to its large size, as well as a lack of resources, trained staff and facilities. This has led to the adoption of other low-cost, easy-to-perform screening methods; VIA is a popular option. Variants of this method include VIA with magnification or with Lugol's iodine. These tests have been demonstrated to be sensitive but not specific (46). The HPV vaccine is not widely available in India at present, mainly due to its cost. A study of the willingness of parents to vaccinate their daughters was performed in Eastern India and reported that, initially, only $40 \%$ of parents agreed to vaccinate their children; this increased to $80 \%$ following a short education session about the vaccine (50). The most common reason stated for refusing the vaccine was the safety of the vaccine, followed by the perception of the vaccine as permission to engage in sexual activity (51). Effective vaccination against HPV 16 and 18 in India is expected to result in a $75 \%$ decrease in the number of cervical cancer cases (47).
Brazil. The poorest regions of Latin America with the lowest resources have high rates of cervical cancer, possibly due to economic, social, educational and geographical factors that limit access to cervical cancer screening (52). Brazil is one of the few countries that have implemented an organised screening program (52). It is predicted that $>8,079$ women die every year in Brazil from cervical cancer (15). HPV infections have been estimated to affect $>5.7 \%$ of women in Brazil and account for $68 \%$ of cervical cancer cases (53). Brazil has a long history of cervical cancer screening programs, the first of which was initiated in 1956 (54). The screening strategy for preventing cervical cancer in Brazil targets women between 25 and 64 years of age. Pap smears are recommended to be repeated every 3 years (55). However, similarly to other developing nations, there is a shortage of resources, especially in trained healthcare professionals, that limits the coverage of the population using cytology-based pap-smear screening. The physical size of the country is another factor limiting screening coverage, which is further complicated by the large population, as there are $>64$ million women aged $>15$ years in Brazil (55). To lower HPV infection rates and control the rates of cervical cancer, the National Health System of Brazil has adopted the quadrivalent HPV vaccine as part of the national vaccination program; the vaccine was adopted in 2014 and is offered to girls between 9 and 13 years of age, and to women infected with HIV between the ages of 9 and 26 years.

\section{Factors that contribute to the development of cervical cancer}

Epigenetic factors. Several factors other than persistent HPV infection contribute to the development and/or progression of cervical cancer, including smoking tobacco (including cigarettes, cigars, pipes, hookah and shisha), high parity, continuous use of oral hormonal contraceptives, promiscuity and co-infection with HIV (Fig. 2) $(1,16,56)$. Of those, high parity and tobacco smoking are the most important contributing factors, as they mediate HR HPV infection progression, which results in high rates of cervical pre-cancer and cancer (57-59). Chatzistamatiou et al (58) identified a significant association between smoking and HR HPV DNA positivity, but not between smoking and the viral HPV 16 E7 oncoprotein in HPV-associated carcinogenesis (58). In addition, the study displayed a higher odds ratio for smokers and ex-smokers compared with that for non-smokers (58). In contrast to non-smokers, continuous cigarette smokers have previously been reported to exhibit higher risk of developing SCC; among women with an increased smoking intensity, those who start smoking at a young age are at higher risk of developing SCC but not AC $(60,61)$. However, Haverkos $(62)$ observed no significant association between cervical cancer and smoking. Therefore, the influence of smoking on increasing the risk of developing cervical cancer remains controversial. However, previous studies have provided evidence of cigarette smoking derivatives acting as causative agents of cervical and lung cancer $(61,63)$.

Co-infection with Chlamydia trachomatis and herpes simplex virus type-2, immunosuppression, and nutritional challenges have also been demonstrated to contribute to cervical cancer development and progression $(1,16)$. Several 


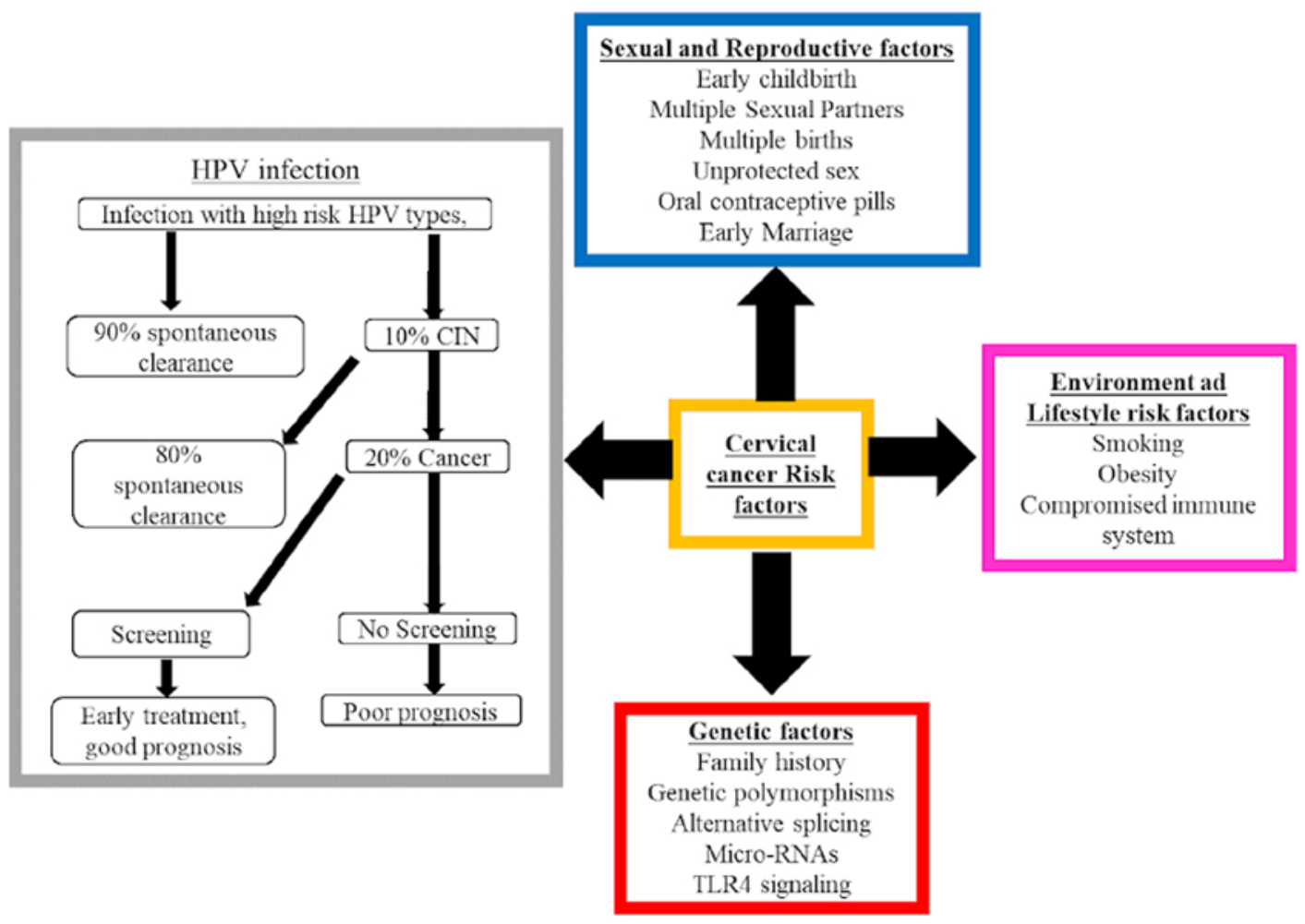

Figure 2. Risk factors associated with the development of cervical cancer. HPV infection is the most important risk factor associated with the development of cervical cancer. The risk of infection with HPV is associated with various sexual and reproductive factors, which further increase the risk of developing cervical cancer. HPV, human papilloma virus; CIN, cervical intraepithelial neoplasia; TLR, toll-like receptor.

genetic and immunological host and viral factors are also predicted as contributing factors (64). Goodson et al (65) identified $>80$ environmental chemicals that serve roles in dysregulating host pathways in carcinogenesis. Environmental risk factors for cervical cancer also include compounds associated with cigarette smoke, such as coal tar derivatives, tar-based vaginal sanitary products and smoke inhaled from biomass-burning stoves (62). These environmental factors can activate signalling pathways responsible for the carcinogenesis of HPV-related cancers, including SCC, in low-income countries (62). These pathways are similar to those known as the hallmarks of cancer, and include hyperproliferative signalling, insensitivity to growth-factor signals, evasion of apoptosis, continuous angiogenesis, genomic unsteadiness, mutation, advanced inflammation and the disruption of normal metabolic functions (65).

In the past decade, the World Health Organization (WHO) reported that billions of individuals from developing regions such as Africa still utilize coal, crop residue, dung and wood for heating and cooking purposes. This is unfortunate because biomass-burning stoves are universally known as a vital source of bio-carcinogens (65). Therefore, women exposed to excessive smoke from these stoves are at greater risk of developing cervical cancer $(16,66)$. This was further verified by Bennett et al (67), who identified an association between the use of solid fuel and cervical cancer.

Coaltar derivatives, such as Lysol, are sometimes used in vaginal sanitary products. The first evidence to associate Lysol usage with cervical cancer was in 1931 when it was noted that the majority of a group of New York women with cervical cancer were continuous users of Lysol sanitizers (62). Lysol is a tar-based derivative, which was initially used in animal research for carcinogenesis (68). A later study amongst Californian women found a significant association between the use of Lysol and cervical cancer (69). Goodson et al (65) also reported that chemical constituents of tobacco (e.g. benzyl pyrenes, polycyclic aromatics and tobacco-based nitrosamines) and tar-based vaginal sanitizers could affect the development of cancer, including cervical cancer, since they penetrate cells and tissues, and stimulate vital carcinogenic pathways. The precise understanding of these pathways may lead to more effective immunotherapeutic strategies and control measures of HPV-related tumours that are usually induced in HR populations exposed to multiple carcinogens due to a low socioeconomic background.

Role of genetic polymorphisms in cervical cancer. Genetic polymorphisms are single nucleotide base changes that occur between two genomes as a deletion, insertion or a substitution of a single nucleotide. These alterations can either be insignificant due to being silent, or they can be highly significant, as they can lead to different types of disorders, such as cervical cancer (70). HPV is considered to be the primary contributory factor to cervical cancer tumour angiogenesis, although a review of previous studies (71) reported additional contributors, including the regulation of long non-coding RNAs (lncRNAs) and/or their gene polymorphisms, such as polymorphisms in toll-like receptor (TLR) genes (72).

LncRNA LINC00673 has been implicated in the development and prognosis of multiple tumours, including SCC (73). 


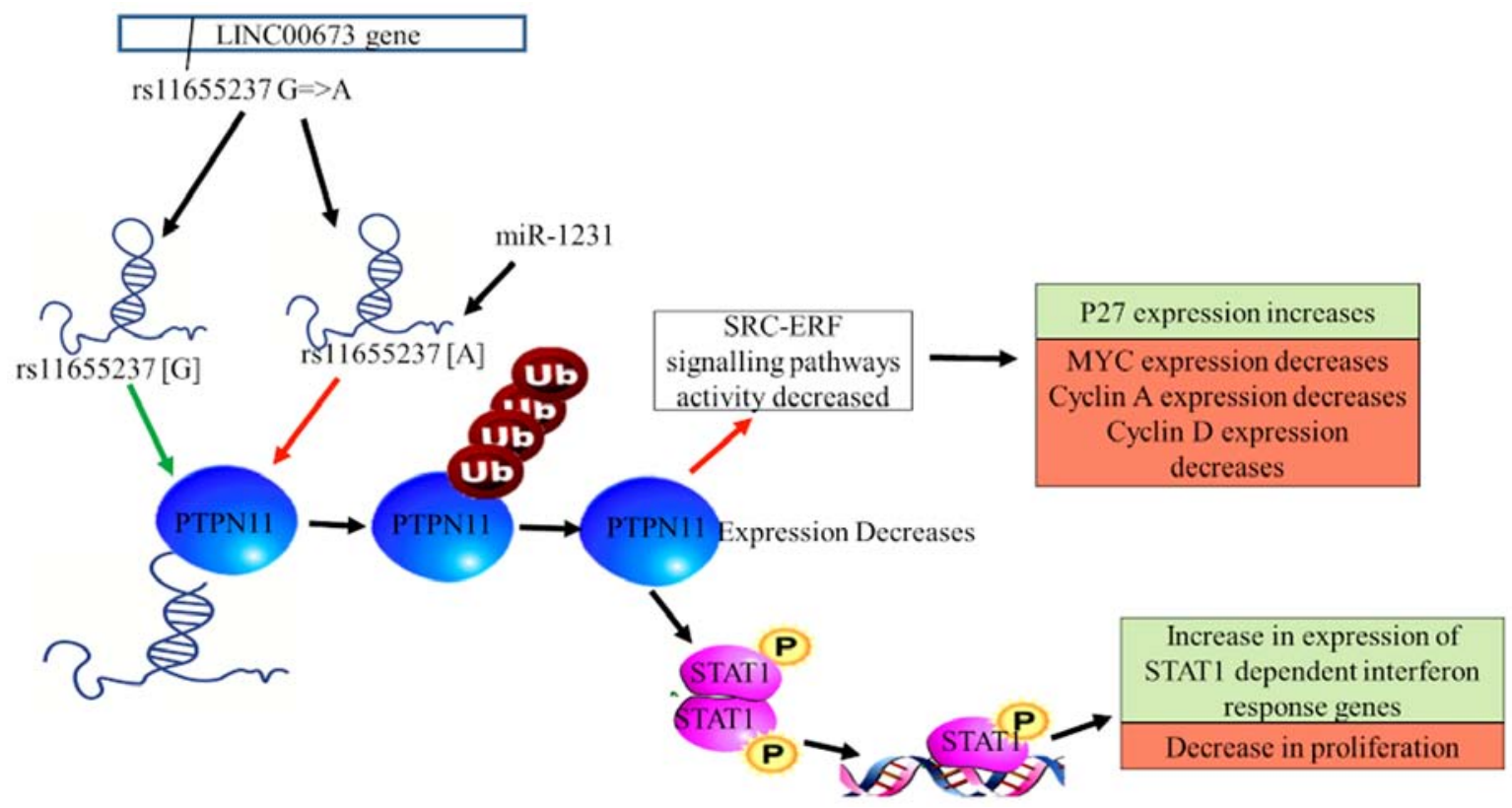

Figure 3. Long non-coding RNA LINC00673 serves an anti-tumour function by controlling PTPN11 degradation. The figure demonstrates how mutations due to SNPs in LINC00673 can promote the development of squamous cell carcinoma. An SNP at position rs11655237 in LINC00673 can increase the risk of developing cervical cancer. A decrease in the level of the normal wild type and an increase in the level of a variant known as LINC00673A that contains a G-to-A nucleotide substitution at rs11655237 may cause dysregulated transcription and result in an increase in the risk of developing cervical cancer. PTPN11, tyrosine-protein phosphatase non-receptor type 11; SRC-ERF, proto-oncogene tyrosine protein kinase-ETS domain-containing transcription factor; STAT, signal transducer and activation of transcription.

In 2018, Wang and Luo (72) demonstrated that the genetic variant of LINC00673 rs11655237 increases vulnerability to cervical cancer in the Chinese population, suggesting that this gene variant is associated with the risk of cervical cancer The study further suggested that downregulation of the transcription levels of LINC00673 rs11655237 in cervical tissues may be the main reason for the association between the genetic variant rs11655237 and the risk of cervical cancer. In addition, a G-to-A nucleotide substitution in the rs 11655237 gene variant of LINC00673 may be the cause of dysregulated transcription, as it generates a target locus for microRNA (miRNA or miR)-1231 attachment, which in turn inhibits LINC00673 $(60,74)$. The A allele and the AA/AG genotype of the rs11655237 gene variant have been demonstrated to be associated with the risk of developing cervical cancer, since the gene variant alters the transcription of LINC00673, which is vital for tumour suppression (Fig. 3) (72).

In 2018, Weng et al (75) investigated the association between the lncRNA HOX transcript antisense intergenic RNA (HOTAIR) genetic polymorphisms and the recurrence of cancer, as well as the survival rates of patients with cervical cancer. Although no significant association was observed between HOTAIR gene polymorphisms and patient clinicopathological characteristics, the study revealed that GG-genotype carriers in the HOTAIR rs920778 gene variant exhibited high risk of cervical cancer recurrence, low predicted survival due to stomal and pelvic lymph node metastasis, and increased mortality compared with carriers of the AA/AG genotype (74-76). Although the AA genotype is not associated with cervical cancer, it is significantly associated with gastric and oesophageal squamous cancer in Chinese populations (77). Therefore, the prognosis of a patient may depend on the impact of HOTAIR expression on the rs920778 gene variant. In addition, since the HOTAIR gene polymorphism rs920778 has insignificant associations with cervical cancer carcinogenesis, it cannot be described as a potential predictive factor for patient prognosis (75).

A previous meta-analysis conducted by Yang et al (78) identified an association between TLR gene polymorphisms and the risk of cervical cancer. The results revealed that white populations carrying the $\mathrm{C}$ allele of the TLR $91486 \mathrm{~T} / \mathrm{C}$ gene polymorphism and the A allele of the TLR 9 G2848A gene polymorphism were significantly associated with an increased risk of developing cervical cancer $(78,79)$. TLR 9 has been previously reported to promote cervical intraepithelial neoplasia (CIN) progression in women from Tunisia (80). These results suggested that TLR 9 may represent a potential biomarker for the malignant transformation of cervical squamous cells. The ability of genes and epigenetic factors to act as contributors of cervical cancer carcinogenesis, and the identification of these factors indicate their potential use in diagnosis and treatment.

\section{Role of alternative splicing in cervical cancer}

Alternative splicing mechanisms. Alternative splicing is a process by which introns are excised (i.e. 'spliced') from pre-mRNA to allow the assembly of exons for translation into a protein (81). The alternative splicing process is imperative to all eukaryotic organisms for the production of multiple alternative isoforms, which are needed for the functional diversity of proteins $(82,83)$. Alternative splicing can undergo several interruptions, such as disturbances associated with miRNA expression, which may lead to several human disorders, including cancer $(84,85)$. In addition, Skotheim and 
Nees (86) have reported that cellular activities such as cell proliferation, motility and drug responsiveness can be negatively affected by the expression of alternative splice variants and tumour-specific variants.

Alternative splicing abnormalities. Abnormalities in alternative splicing have been demonstrated to lead to the development of multiple human diseases such as cancer, heart disease, and age-associated diseases, HIV-associated nephropathy and autoimmune disorders (87). Aberrant alternative splicing is usually a result of genomic point mutations that occur in splicing factors or elements that result in transcriptome alterations such as exon alteration, intron retention and gene expression changes (Fig. 4) (83). These mutations and alterations normally affect multiple protein pathways and mRNA expression $(83,88)$. The influence of aberrant alternative splicing in the majority of cancer types results from splicing factor mutations in cancer genes or transcripts of non-mutated genes (89). Genome-wide associated studies have demonstrated the association of the splicing factor $3 \mathrm{~A}$ subunit 1 (SF3A1) gene (which is located on 22q12.3) with several diseases, including lung and breast cancer, as well as inflammatory bowel disease $(90,91)$. Mutations in the SF3A1 coding region are associated with susceptibility to multiple types of cancer, including oesophageal AC, osteosarcoma, myxoid liposarcoma, synovial sarcoma, ovarian carcinoma, glioblastoma, endometrial, lung, breast and gastric cancer (92).

Expression studies by Liu et al (93) demonstrated the ability of HR HPV oncoproteins E6 and E7 to induce the expression of serine- and arginine-rich splicing factor 10 (SRSF10), which is crucial for HPV 16- and 18-positive cervical carcinogenesis. Increased levels of SRSF10 were induced by E2F transcription factor 1 (93). The synthesis of the membrane form of interleukin-1-receptor accessory protein (mIL1RAP) is controlled by SRSF10 through the modulation of alternative splicing of the IL1RAP exon 13. This gives rise to the interleukin $1 \beta$ isoform, which induced $\mathrm{NF}-\kappa \mathrm{B}$ transcription of the CD47 receptor. This cell surface molecule signals cells to escape macrophage phagocytosis (Fig. 5) (93). The study further revealed a significant association amongst SRSF10, mIL1RAP and CD47 expression in tissues of the uterus (93). This revealed that alternative splicing, inflammatory molecules and immune scrutiny served crucial roles in HPV 16/18-positive carcinogenesis $(93,94)$. These results suggested that proteins associated with cervical cancer need to be researched for splice site abnormalities, since this method can also be used as a screening tool for the disease.

TLR mechanisms that lead to cervical cancer. TLRs are pattern recognition receptors that function in innate immune responses by identifying conserved components of microorganisms known as pathogen-associated molecular patterns. Previous studies have indicated that TLRs are expressed in tumour cells and in the tumour microenvironment of various types of cancer (95). TLR 3 (96), TLR 4 (96), TLR 5 and TLR 9 (96) have been identified in cervical cancer tissues, indicating that they may be involved in the occurrence of the disease. TLRs are activated by ligands such as lipids, and have been demonstrated to serve an important role in the development
Table IV. TLR expression in different types of cancer (97).

\begin{tabular}{ll}
\hline Cancer type & \multicolumn{1}{c}{ TLRs } \\
\hline Cervical & TLR 3, TLR 4, TLR 5, TLR 9 \\
Gastric & TLR 2, TLR 4, TLR 5, TLR 9 \\
Colorectal & TLR 2, TLR 3, TLR 4, TLR 5, TLR 9 \\
Ovarian & TLR 2, TLR 3, TLR 4, TLR 5 \\
Lung & TLR 2, TLR 3, TLR 4, TLR 9 \\
Prostate & TLR 4, TLR 9 \\
Breast & TLR 2, TLR 3, TLR 4, TLR 9 \\
Liver & TLR 2, TLR 3, TLR 4, TLR 6, TLR 9 \\
Pancreatic & TLR 2, TLR 4, TLR 9 \\
\hline
\end{tabular}

TLR, toll-like receptor.

and progression of cervical cancer (97). These protein receptors are also expressed in other tumours (98), indicating that they may bind different ligands (Table IV). TLRs are highly expressed in immune and cancerous cells $(80,99)$. Persisting HPV infection is the major cause of cervical cancer; however, alterations in expression levels of TLRs are suspected to also serve a significant role in HPV infection-induced cervical cancer (80). In support of this, Fehri et al (80) analysed the expression of TLR 9 in 53 samples from Sian women with ICC, CIN, condyloma and normal cervical tissues; the results revealed statistically significant differences in CIN and ICC between condyloma and normal healthy tissues. Almost all patients with ICC exhibited a higher level of TLR 9 expression in tumour epithelial cells, whereas between $50-80 \%$ of patients with CIN and condyloma exhibited weaker TLR expression (80). These results supported previous studies on Korean, Chinese and Canadian populations, which also revealed low TLR 9 expression in CIN and high TLR 9 expression in ICC $(100,101)$. High expression levels of TLR 9 were mainly observed in the absence of HPV and/or its clearance (102). Hasan et al $(103,104)$ reported that HPV subtype 16 proteins E6 and E7 dysregulated TLR 9 expression and functions. This suggested that HPV may use TLR 9 dysregulation to suppresses its function of viral DNA recognition, as TLR 9 is a crucial recognition receptor for DNA-introducing pathogens, particularly DNA viruses; in addition, it promotes inflammatory and immune responses $(99,105)$. The results indicated the potential role of TLR 9 in CIN progression among women from various populations, suggesting that it may be used as a biomarker for SCC transformation.

TLR 9 signalling induces tumour progression, survival and immune evasion in various cancer types, including cervical cancer (106). However, whether TLR 9 promotes or suppresses tumour growth remains unknown. Better understanding of the TLR 9 signalling pathway in cervical cancer may aid in the development of new immunotherapeutic strategies (80).

The combination of TLR 4 and the ligand lipopolysaccharide may trigger lipid raft flow that leads to the alteration of the lipid raft space conformation (Fig. 6A) (107). The change in the conformation of lipid rafts results in the aggregation of NADH oxidase subunits on lipid rafts, inducing a redox reaction of 


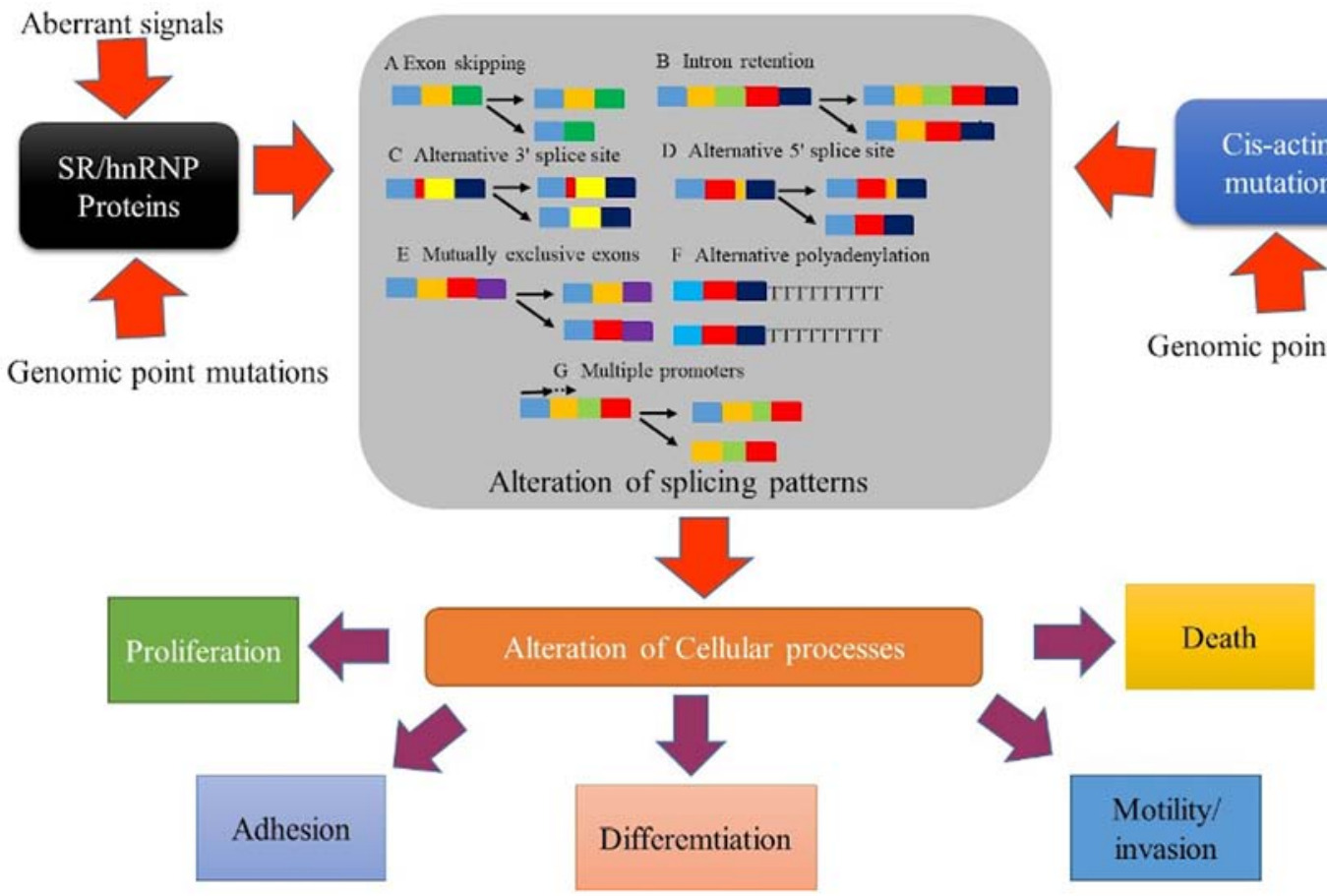

Figure 4. Pathways of aberrant alternative splicing resulting in diseases such as cervical cancer. The flow chart depicts the causes, mechanisms and results of aberrant alternative splicing. Aberrant alternative splicing is caused by genomic point mutations in splicing factors or elements. These lead to changes in splicing and different populations of splice variants, such as exon alteration, intron retention, alteration in $3^{\prime}$ and $5^{\prime}$ splicing, mutually exclusive introns, alteration in polyA tail length or occurrence of multiple promoters. Aberrant alternative splicing can contribute to a variety of pathologies. SR protein, serine arginine domain splicing factors; hnRNP, Heterogeneous nuclear ribonucleoproteins.

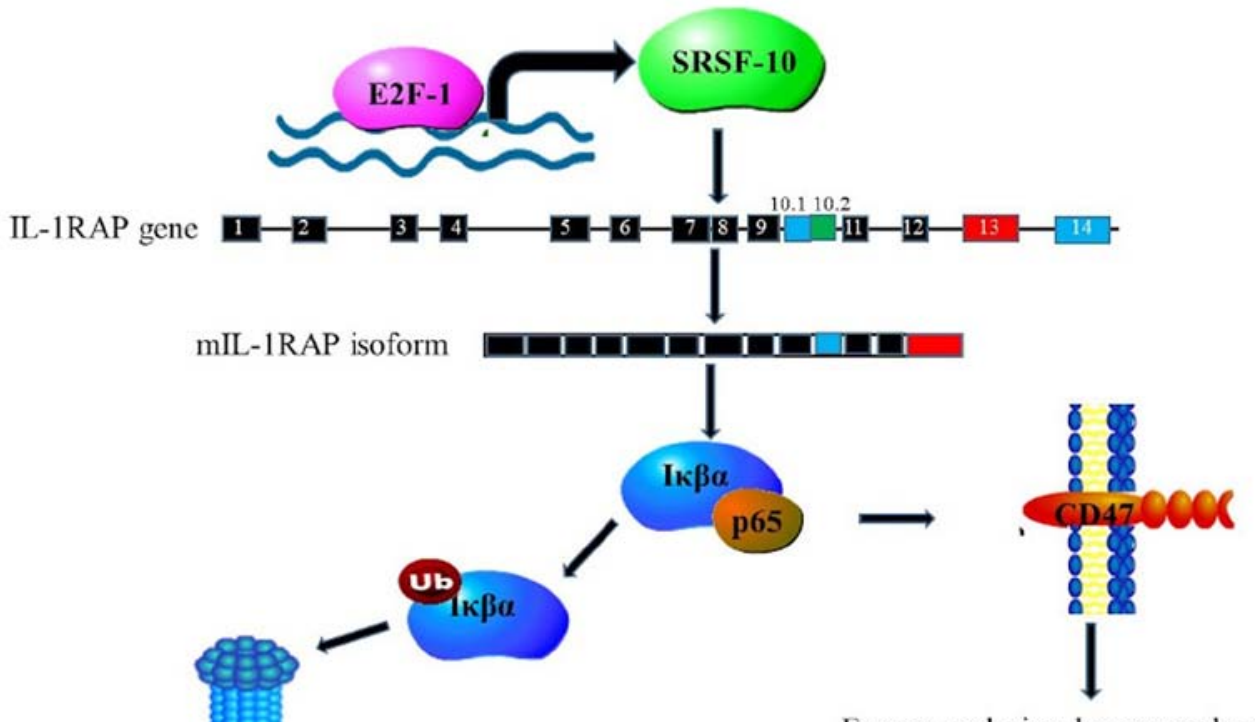

Escape exclusion by macrophage phagocytosis

Degredation by the proteosome

Figure 5. Aberrant alternative splicing of the IL1RAP gene leads to immune evasion and development of cervical cancer. The synthesis of mIL1RAP is controlled by the SRSF10 splicing factor. This allows the alternative splicing of the iLIllrap exon 13 to form the mRNA corresponding to the membrane-bound isoform. This stimulates the IL-1 $\beta$-induced NF-kB-mediated transcription of CD47, allowing the tumour cells to avoid phagocytosis by macrophages. CD47, CD antigen 47; E2F1, E2 Transcription factor 1; IкB $\alpha$, nuclear factor of kappa light polypeptide gene enhancer in B-cells inhibitor, alpha; IL1RAP, interleukin-1-receptor accessory protein; mIL1RAP, membrane form of interleukin-1-receptor accessory protein; p65, transcription factor 65; SRSF10, serine- and arginine-rich splicing factor 10.

lipid rafts to produce reactive oxygen species and the inhibition of hypoxia-inducible factor $1 \alpha$ degradation, which may lead to the induction of cervical cancer (Fig. 6B) (97).
miRNA in cervical cancer. miRNAs are a group of small non-coding RNAs of 18-25 nucleotides in length that regulate gene expression at the post-transcriptional level (108). miRNAs 


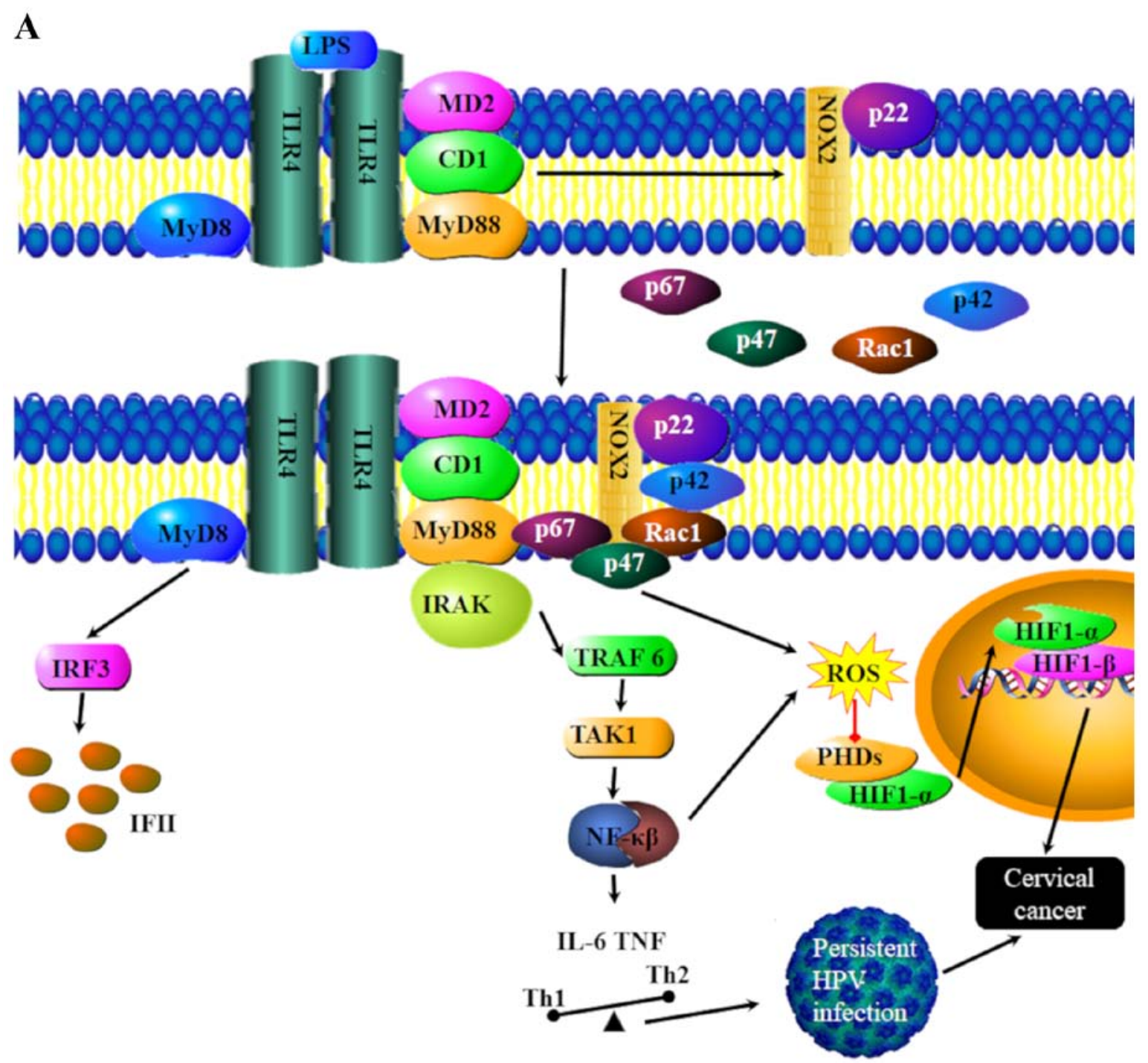

Figure 6. TLR4 signaling pathways in cervical cancer. (A) Binding of LPS to TLR4 leads to the transmission of signals via MyD88, At the same time the activation of TLR5 leads to increased Nox1 signaling.

also serve crucial functions in cell proliferation, differentiation, migration, invasion and drug resistance $(78,109-111)$. The translation of mRNA can be suppressed or degraded when their 3'-untranslated regions (3'-UTRs) are targeted by miRNAs $(93,112-114)$. Abnormal miRNA expression has been reported to contribute to the progression of multiple types of cancer, including breast, lung, oesophageal and ovarian cancer (115-120).

Expression of miR-214 in cervical cancer. Several miRNAs serve significant roles in the development of cancer, such as miR-98 (121), miR-98 (121), miR-146b-5p (122) and miR-214 (122). miR-214 has been demonstrated to be associated with both the inhibition and progression of multiple types of cancer, including cervical cancer (78). Yang et al (78) analysed the expression levels of miR-214 in cervical cancer and non-cancerous tissues. The results revealed that the inhibition of miR-214 expression in cancerous tissue stimulated cervical cancer proliferation, whereas excessive expression of miR-214 inhibited cancer progression (78). MTT assays were performed on cervical cancer cells revealed a significant inversely proportional association between the expression levels of miR-214 and enhancer of zeste homolog 2 (EZH2); increased expression levels of miR-214 and reduced expression levels of EZH2 resulted in reduced cervical cancer cell proliferation, whereas low expression of miR-214 combined with high EZH2 expression resulted in increased cervical cancer cell proliferation in vitro (78). Thus, the differential expression levels of miR-214 suggest that it may be a potential biomarker for prognosis and diagnosis of cervical cancer, or a tool for treatment of this disease. Statistical analysis determined an association between miR-214 expression levels and the survival rates of patients with cervical cancer (78). Patients expressing low levels of of miR-214 exhibited enhanced levels of cervical cancer proliferation. Moreover, patients with higher expression levels of miR-214 exhibited improved survival rates. A decrease in the EZH2 expression levels was significantly associated with the inhibition of cervical cancer proliferation (78).

Expression of miR-217 in cervical cancer. Previous studies have revealed that miRNAs act as tumour suppressors in 
B
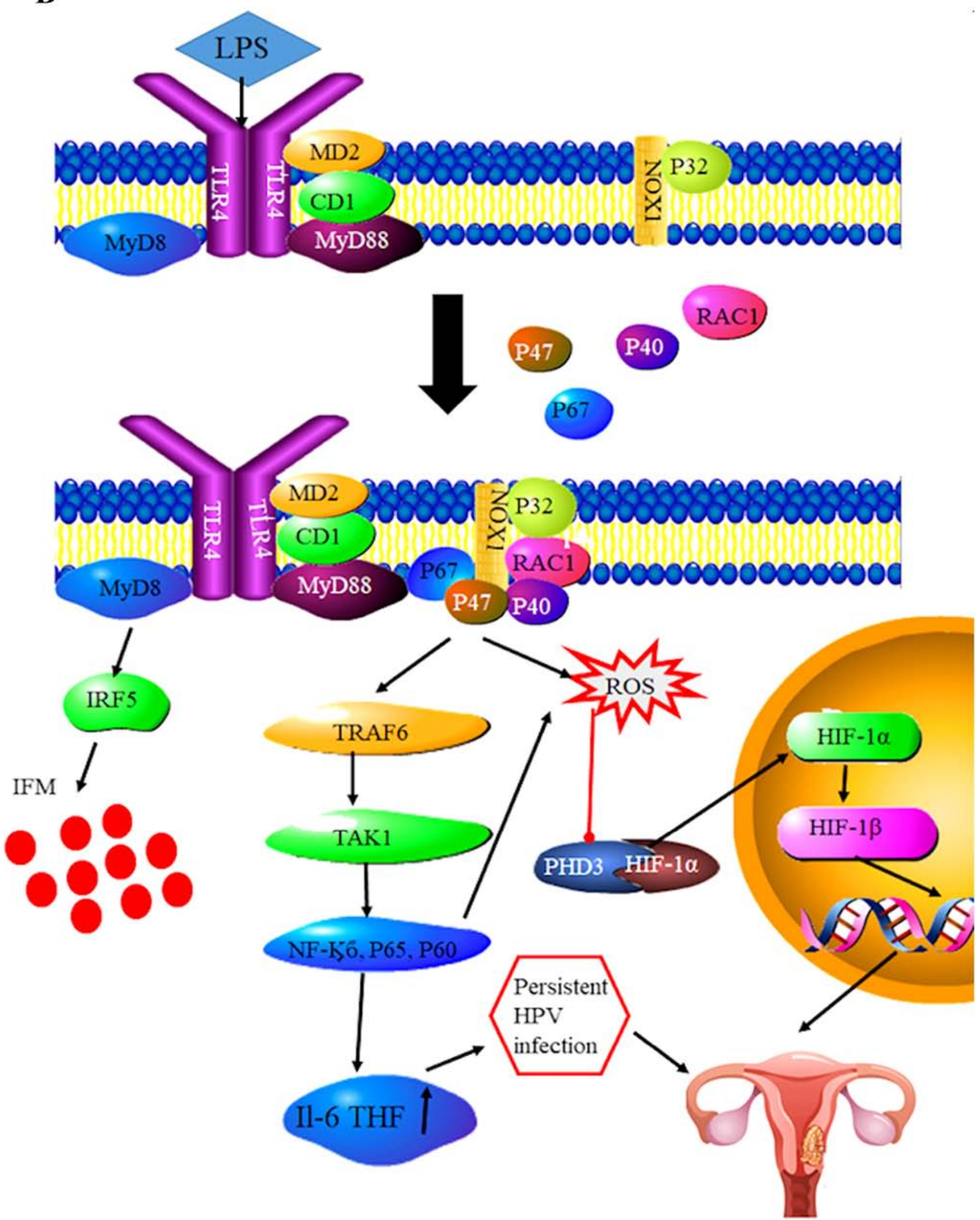

Cervical cancer

Figure 6. Continued. (B) The primary role of NOX1 is to generate ROS. NOX1 signaling also leads to the inhibition of HIF-1 $\alpha$ degradation, which increases the possibly of developing cervical cancer MyD88 signaling in conjunction with NOX1 leads to the activation of transcription factors and Interfrons (IFN), leading to a pro-inflammatory and antiviral response. This pathway demonstrates how inflammation can lead to cancer progression. CD1, cluster differentiation 1; HIF-1 $\alpha$, hypoxia inducible factor 1 $\alpha$; IL-6, interleukin 6; IFN, interferon; IRAK, interleukin-1 receptor-associated kinase; IRF3, interferon regulatory factor 3; LPS, lipopolysaccharides; MyD8, myeloid differentiation primary response 8; MyD88, myeloid differentiation primary response 88; NF-кB, nuclear factor kappa-light-chain-enhancer of activated B cells; Nox1, NADPH oxidase 1; PHDs, propyl hydroxylases; Rac1, ras-related C3 botulinum toxin substrate 1; TAK1, transforming growth factor beta-activated kinase 1; TLR, toll-like receptor; Traf6, tumor necrosis factor receptor (TNFR)-associated factor 6; NADH, nicotinamide adenine dinucleotide hydrogen. 


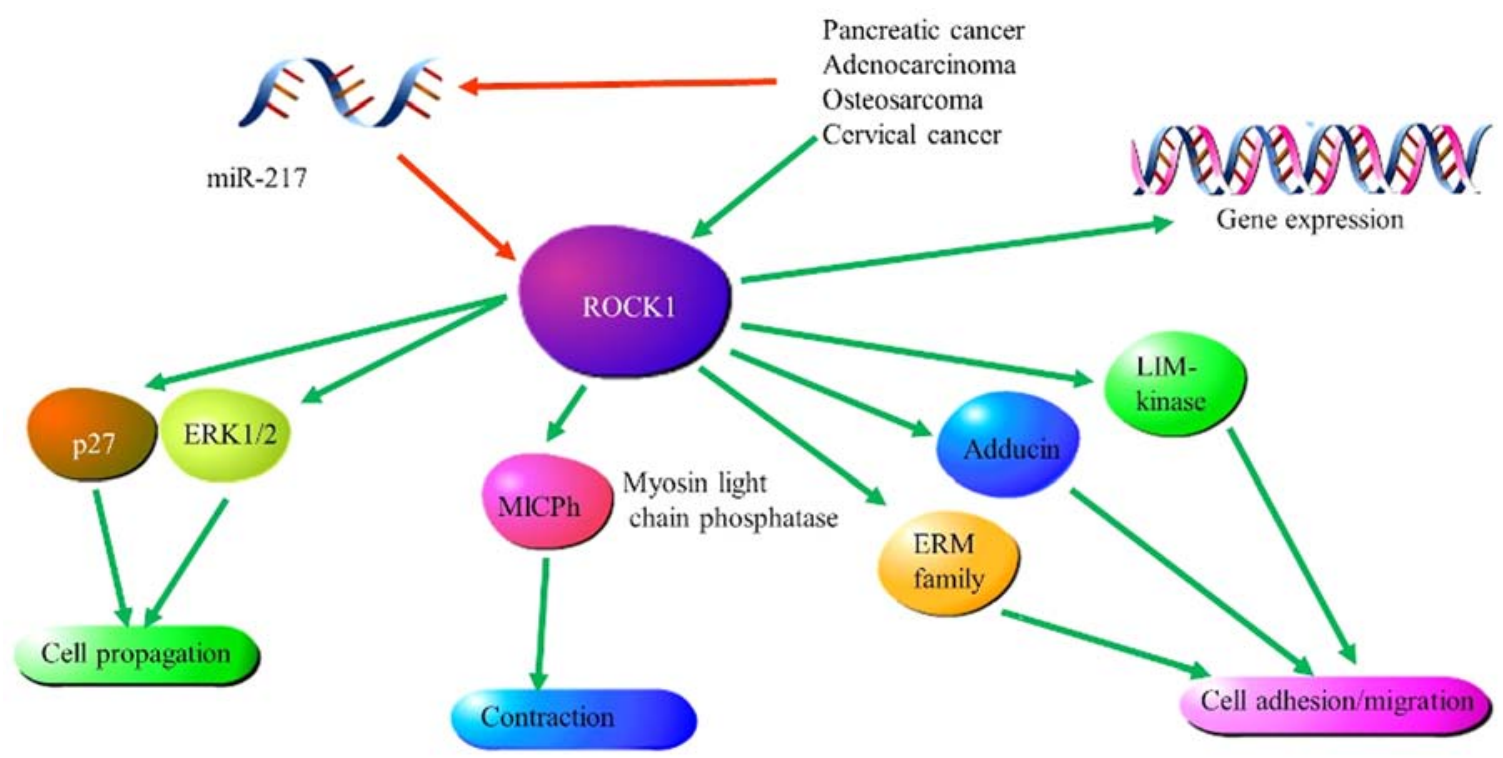

Figure 7. Increased expression of ROCK1 in cancer may be due to decreased levels of miR-217. ROCK1 expression is regulated by miR-217. Lower transcript levels of this miRNA are associated with metastatic and non-metastatic cervical cancer. Overexpression of miR-217 significantly inhibits cell growth. ROCK1 leads to increased invasion and metastasis. ERK, extracellular signal-regulated kinases; ERM, ezrin, radixin and moesin; LIM kinase, Lin11, Isl-1 and Mec-3 kinase; miR, microRNA; MLC phosphatase, myosin light-chain phosphatase; ROCK1, rho-associated coiled-coil containing protein kinase 1.

cervical cancer cells by regulating specific target genes. For example, Dong et al (123) compared Rho-associated coiled-coil containing protein kinase 1 (ROCK1) expression levels in cervical cancer and non-cancerous tissues and cell lines. Significantly lower expression levels of miR-217 were observed in metastatic and non-metastatic cervical cancer tissues and cell lines compared with those in non-cancerous tissues and cell lines (123). Reduced invasive capabilities of SiHa and HeLa cell lines, as well as reduced colony formation, was demonstrated when miR-217 was highly expressed; in addition, the effect of high miR-217 expression on apoptosis in $\mathrm{SiHa}$ and HeLa cell lines was analysed by flow cytometry. The flow cytometry indicated that increased transcription of miR-217 in cells resulted in a greater proportion of these cells undergoing apoptosis (123). Overexpression of miR-217 significantly inhibited cell growth, whereas overexpression of ROCK1 increased cell invasive abilities in the SiHa cell line due to decreased miR-217 expression (123). Therefore, the ability of miR-217 to suppress cervical cancer may be modulated through ROCK1. This was further supported by suppressed luciferase activity of pmirGLO-ROCK1-3'UTR-1 and pmirGLO-ROCK1-3'UTR-2 following overexpression of miR-217 (123). Lastly, western blot analysis revealed that overexpression of miR-217 significantly lowered ROCK1 expression levels, whereas reduced levels of miR-217 expression resulted in increased ROCK1 expression levels (Fig. 7) (120). Therefore, miR-217 may target ROCK1 to inhibit cervical cancer proliferation (123). The level of miRNA transcription serves an important role in cervical cancer progression, which in turn highlights the importance of broadening our knowledge on potential miRNA target genes, as well as the potential mechanisms of migration and invasion for the identification of potential prognostic and diagnostic tools, and for the development of novel immunotherapeutic strategies for cervical cancer.

\section{Prevention and diagnosis of cervical cancer}

Geographic variation in cervical cancer incidence is based in part on differences in the availability of screening to allow for the early identification and removal of precancerous lesions. The diagnosis of HPV should also be considered as an important and challenging causative factor for cervical cancer that varies geographically (124).

Cervical cancer prevention: HPV vaccination. In 2013, Adesina et al (125) estimated that 11 million women in Sub-Saharan Africa would be diagnosed with cervical cancer within the next 10-20 years, with $\sim 1.7$ million cases diagnosed in 2010 (126). Prevention of cervical cancer is regarded as the best control method; however, treatment is also an important intervention (127). A cost-effective HPV vaccine has been reported as lifesaving amongst girls between 9 and 12 years of age (50). The number of cervical cancer cases are predicted to effectively decrease after five decades of comprehensive vaccination (128). There are two types of HPV vaccines used for targeting the predominant subtypes of HPV: The bivalent vaccine, which targets the HPV 16 and 18 subtypes, and the quadrivalent vaccine, which targets the HPV 6, 11, 16 and 18 subtypes $(2,129)$. HPV vaccines have been reported to effectively assist in preventing HPV infection, and result in the prevention of CIN $(130,131)$ HPV vaccination first became popular in high-income countries but remained unpopular in low income countries due to the high price of the vaccine. Since 2011, HPV vaccinations have gained popularity in middle-income countries due to a decrease in cost (2); since 2012, increased financial support for HPV vaccination projects in low-income countries has enabled such countries to adopt vaccination programs $(2,132)$. HPV vaccination for women in South Africa was first introduced in 2014 through the National HPV Immunization Program. The primary target age for HPV vaccination in South Africa is 9 years 
(pupils in grades 3 and 4) (6,17). According to the European Medicines Agency, the standard dose for girls $<14$ years of age is two doses at 0 and $<6$ months depending on whether they are receiving the Cervarix or Gardasil vaccine (21). Herrero et al $(2,7)$ clinically demonstrated that three doses of HPV vaccine can provide total protection against persisting HPV infection and associated precancerous lesions in women aged between 15 and 26 years old, provided that they have not been previously exposed to the virus (7). Therefore, treatment (or vaccination) and screening is crucial for lowering the incidence, burden and mortality rates of cervical cancer (7).

Cervical cancer screening. It is of great global interest to eliminate or decrease the number of new cases and high mortality of cervical cancer caused by persistent HPV infection. Therefore, Pap smear screening for cervical cancer is highly encouraged during the HIV diagnosis process. This procedure should be repeated every 3 years for women who have been previously screened and diagnosed as negative (50). Regular screening for cervical cancer amongst women is predicted to lower the lifetime risk of developing the disease (133). Population screening for cervical cancer in regions of low socioeconomic status and low-resource settings remains elusive; the cervical cancer screening coverage in Southern Africa ranges between 4.1 and $38.0 \%$. A study of 642 females in urban areas found that $17.3 \%$ had been screened, while of 580 females in rural areas $9.6 \%$ had been screened for HPV $(130,134,135)$. This low coverage is due to factors such as inaccessibility (due to areas being remote), lack of funding, community awareness and cost-effectiveness, complications of Pap smear, a lack of public policy attention, or the implementation of ineffective public policies $(128,130,136)$.

HIV-associated cervical cancer incidence is predicted to gradually increase in LMICs for the next 10 years (137). Despite the incidence of cervical cancer in many LMICs being lower than in many developed countries, the cancer burden in LMICs is increasing due to the advanced stage at diagnosis and inaccessible treatment (28). Thus, immediate action in the public and global health sectors is advised $(2,138)$. Effective precancerous lesion detection using the PapilloCheck ${ }^{\circledR}$ microarray and the HPV restriction fragment length polymorphism (RFLP) PCR assay was achieved with 62.5 and $25.0 \%$ HPV co-infection detection, respectively (4). The RFLP PCR assay is suggested as a primary HPV test for screening in LMICs, as it is cost-effective, while the PapilloCheck ${ }^{\circledR}$ microarray assay is considered a more sensitive and descriptive test (4). However, widespread access to screening at the population level in LMICs remains challenging. For example, in Uganda, cervical cancer is the leading type of cancer amongst women, with 3,915 new cases and 2,275 deaths per year (21); however, $<10 \%$ of Ugandan women have ever been screened (139).

Several studies have reported multiple compounding factors that contribute to non-participation of women in cervical cancer screening, such as unemployment, lack of or low education level, poor language proficiency (for example, the information and education campaigns not being provided in the native language of the women the programs are aimed at), being unmarried, lack of knowledge of screening, previous negative experiences of screening, cultural and traditional beliefs, and multiple other determinants (140-142). Thus, the WHO and the European Commission have recognised that equal access and equal utilization of healthcare is essential to deal with inequity issues in healthcare (143). This may improve healthcare service practices such as screening and treatment $(144,145)$. In conclusion, appropriate cervical cancer screening programs and good-quality cytological testing can assist in lowering the incidence and mortality rates of cervical cancer. The effectiveness of prevention and treatment programs is dependent on equity in healthcare and good healthcare service practices. A lack of cervical cancer screening is not the sole cause for the high burden of cervical cancer in LMICs. Another important consideration is the decision on whether to treat a patient based on a positive result for an HPV test. Since most HPV infections clear spontaneously, especially in younger women, if a patient is treated without further screening, it may contribute to unnecessary treatment costs (146).

\section{Conclusions}

Globally, Southern Africa displays the largest HIV burden amongst women, contributing to it being a HR region for developing an HPV infection, pre-invasive cervical disease and ICC. Poor prognosis and diagnosis are common in low-income settings, where women experience advanced stages of HPV infection and lack treatment.

Control methods, including Pap smear screening and HPV vaccines, have been used to help reducing the exponential increase in new cervical cancer cases, although the low coverage for screening remains a challenge in a number of LMICs. However, these control methods were initially only available in developed countries and have only recently become available in middle-income countries, leaving women from low socioeconomic backgrounds vulnerable. This is caused by the lack of funding and accessibility to cost-effective treatment. Thus, the present review highlights the importance of equity in the access and utilization of healthcare services and products.

Although HPV vaccines have been introduced in multiple LMICs, their prophylactic efficacy is only beneficial to women who have not been exposed to the virus; therefore, this identifies a need for further research into other possible interventions, particularly for those already infected. The effect of aberrant alternative splicing on cervical cancer requires further research and may be a promising tool for treatment of the disease. Similarly, TLRs and miRNAs may be explored further as potential immunotherapeutic interventions.

\section{Acknowledgements}

Not applicable.

\section{Funding}

The present study was supported by the Medical Research Council of South Africa, through the SA-MRC/UP Precision Prevention and Novel Drug Targets for HIV-Associated Cancers Extramural Unit Grant and the SA-MRC SHIP Grant. 


\section{Availability of data and materials}

Not applicable.

\section{Authors' contributions}

ZD was responsible for the Acquisition of funding. RH, MM, $\mathrm{RM}$ and ZMK were responsible for the collection of data. $\mathrm{RH}$, MM, TM, RM and ZMK were responsible for writing the manuscript. RH, TM, RM, ZMK, CH, SMW, RMR, GK and DOB were responsible for editing/revising the manuscript. ZD is responsible for supervising the research group. The review was written by RH, MM, TM, RM, ZMK and ZD. All authors read and approved the final manuscript.

\section{Ethics approval and consent to participate}

Not applicable.

\section{Patient consent for publication}

Not applicable.

\section{Competing interests}

The authors declare that they have no competing interests.

\section{References}

1. Torre LA, Bray F, Siegel RL, Ferlay J, Lortet-Tieulent J and Jemal A: Global cancer statistics, 2012. CA Cancer J Clin 65 : 87-108, 2015

2. Herrero R, González P and Markowitz LE: Present status of human papillomavirus vaccine development and implementation. Lancet Oncol 16: e206-e216, 2015.

3. Waggoner SE: Cervical cancer. Lancet 361: 2217-2225, 2003.

4. Golfetto L, Alves EV, Martins TR, Sincero TCM, Castro JBS Dannebrock C, Oliveira JG, Levi JE, Onofre ASC and Bazzo ML: PCR-RFLP assay as an option for primary HPV test. Braz J Med Biol Res 51: e7098, 2018.

5. Bruni L, Diaz M, Castellsagué X, Ferrer E, Bosch FX and de Sanjosé S: Cervical human papillomavirus prevalence in 5 continents: Meta-analysis of 1 million women with normal cytological findings. J Infect Dis 202: 1789-1799, 2010.

6. Kocjan BJ, Bzhalava D, Forslund O, Dillner J and Poljak M: Molecular methods for identification and characterization of novel papillomaviruses. Clin Microbiol Infect 21: 808-816, 2015.

7. Ghebre RG, Grover S, Xu MJ, Chuang LT and Simonds H: Cervical cancer control in HIV-infected women: Past, present and future. Gynecol Oncol Rep 21: 101-108, 2017.

8. Ferlay J, Soerjomataram I, Dikshit R, Eser S, Mathers C, Rebelo M, Parkin DM, Forman D and Bray F: Cancer incidence and mortality worldwide: Sources, methods and major patterns in GLOBOCAN 2012. Int J Cancer 136: E359-E386, 2015.

9. Idehen EE, Koponen P, Härkänen T, Kangasniemi M, Pietilä AM and Korhonen T: Disparities in cervical screening participation: A comparison of Russian, Somali and Kurdish immigrants with the general Finnish population. Int J Equity Health 17: 56, 2018.

10. Swanson M, Ueda S, Chen LM, Huchko MJ, Nakisige C and Namugga J: Evidence-based improvisation: Facing the challenges of cervical cancer care in Uganda. Gynecol Oncol Rep 24: 30-35, 2018.

11. Satterwhite CL, Torrone E, Meites E, Dunne EF, Mahajan R, Ocfemia MC, Su J, Xu F and Weinstock H: Sexually transmitted infections among US women and men: Prevalence and incidence estimates, 2008. Sex Transm Dis 40: 187-193, 2013.
12. Say L, Chou D, Gemmill A, Tunçalp Ö, Moller AB, Daniels J, Gülmezoglu AM, Temmerman M and Alkema L: Global causes of maternal death: A WHO systematic analysis. Lancet Glob Health 2: e323-e333, 2014.

13. Bray F, Ren JS, Masuyer E and Ferlay J: Global estimates of cancer prevalence for 27 sites in the adult population in 2008. Int J Cancer 132: 1133-1145, 2013.

14. Torre LA, Islami F, Siegel RL, Ward EM and Jemal A: Global cancer in women: Burden and trends. Cancer Epidemol Biomarkers Prev 26: 444-457, 2017.

15. Bray F, Ferlay J, Soerjomataram I, Siegel RL, Torre LA and Jemal A: Global cancer statistics 2018: GLOBOCAN estimates of incidence and mortality worldwide for 36 cancers in 185 countries. CA Cancer J Clin 68: 394-424, 2018.

16. World Health Organization: WHO guidelines for screening and treatment of precancerous lesions for cervical cancer prevention. World Health Organization, 2013. https://www.who.int/ reproductivehealth/publications/cancers/screening and treatment of_precancerous_lesions/en/. Accessed March 16, 2019.

17. Karsa LV, Anttila A, Ronco G, et al: Cancer screening in the European Union. Report on the implementation of the Council Recommendation on cancer screening. In: Cancer screening in the European Union. Report on the implementation of the Council Recommendation on cancer screening. European Commission, Luxembourg, pp 160, 2008.

18. Ginindza TG and Sartorius B: Projected cervical cancer incidence in Swaziland using three methods and local survey estimates. BMC Cancer 18: 639, 2018.

19. Ferlay J, Colombet M, Soerjomataram I, et al: Estimating the global cancer incidence and mortality in 2018: GLOBOCAN sources and methods. Int J Cancer 144: 1941-1953, 2019.

20. Sartorius K, Sartorius B, Aldous C, Govender PS and Madiba TE: Global and country underestimation of hepatocellular carcinoma (HCC) in 2012 and its implications. Cancer Epidemiol 39: 284-290, 2015.

21. Nakisige C, Schwartz M, Ndira AO. Cervical cancer screening and treatment in Uganda. Gynecol Oncol Rep 20: 37-40, 2017.

22. Ferlay J, Ervik M, Lam F, Colombet M, Mery L, Piñeros M, Znaor A, Soerjomataram I, Bray F (2018). Global Cancer Observatory: Cancer Today. Lyon, France: International Agency for Research on Cancer. https://gco.iarc.fr/today/ online-analysis-map? $\mathrm{v}=2018 \&$ mode $=$ population\&mode_popu lation $=$ continents \&population $=900 \&$ populations $=900 \&$ key $=$ asr $\&$ sex $=2 \&$ cancer $=23 \&$ type $=0 \&$ statistic $=5 \&$ prevalence $=0 \&$ population group $=0 \&$ ages group $\% 5 \mathrm{~B} \% 5 \mathrm{D}=0 \&$ ages group $\% 5 \mathrm{~B} \% 5 \mathrm{D}=17 \& \mathrm{nb} \_$items $=10 \&$ group_cancer $=1 \&$ include nmsc $=1 \&$ include_nmsc_other $=1 \&$ projection $=$ globe \& color palette $=$ default $\&$ map_scale $=$ quantile $\&$ map_nb_colors $=5 \&$ cont inent $=0 \&$ rotate $=\% 255 \mathrm{~B} 10 \% 252 \mathrm{C} 0 \% 255 \mathrm{D}$. Accessed March 18, 2019.

23. International Agency for Research on Cancer: GLOBOCAN 2012: Estimated cancer incidence, mortality and prevalence worldwide in 2012. 2012. https://www.iarc.fr/news-events/ latest-world-cancer-statistics-globocan-2012-estimated-cancerincidence-mortality-and-prevalence-worldwide-in-2012/.

24. Chibwesha CJ, Goeieman B, Levin S, Mulongo M, Faesen M, Swarts A, Ramotshela S, Williams S, Rakhombe N, Bruce $S$, et al: Estimating the burden of cervical disease among HIV-infected women accessing screening services in South Africa: A model-based analysis. S Afr Med J 108: 235-239, 2018.

25. Simonds HM, Wright JD, du Toit N, Neugut AI and Jacobson JS: Completion of and early response to chemoradiation among human immunodeficiency virus (HIV)-positive and HIV-negative patients with locally advanced cervical carcinoma in South Africa. Cancer 118: 2971-2979, 2012.

26. UNAIDS: UNAIDS Terminology Guidelines. http://www. unaids.org/en/media/unaids/contentassets/documents/unaidspublication/2011/JC2118_terminology-guidelines_en.pdf. Accessed June 13, 2019.

27. UNAIDS: Report on the global HIV/AIDS epidemic. UNAIDS2002. http://data.unaids.org/pub/report/2002/brglobal_ aids_report_en_pdf_red_en.pdf. Accessed June 13, 2019.

28. Jacobson G, Chuang L and Pankow M: Improving quality of care and timely access to radiation therapy for patients with invasive cervical cancer at the National Cancer Institute Paraguay. Gynecol Oncol Rep 25: 82-86, 2018.

29. Bosch FX, Broker TR, Forman D, Moscicki AB, Gillison ML, Doorbar J, Stern PL, Stanley M, Arbyn M, Poljak M, et al: Comprehensive control of human papillomavirus infections and related diseases. Vaccine 31 (Suppl 7): H1-H31, 2013. 
30. Forman D, de Martel C, Lacey CJ, Soerjomataram I, Lortet-Tieulent J, Bruni L, Vignat J, Ferlay J, Bray F, Plummer M, et al: Global burden of human papillomavirus and related diseases. Vaccine 30 (Suppl 5): F12-F23, 2012.

31. Ginsburg O, Bray F, Coleman MP, Vanderpuye V, Eniu A, Kotha SR, Sarker M, Huong TT, Allemani C, Dvaladze A, et al: The global burden of women's cancers: A grand challenge in global health. Lancet 389: 847-860, 2017.

32. Fields MM: New cervical cancer screening guidelines: Was the annual pap too much of a good thing? J Adv Pract Oncol 4 59-64, 2013

33. Moyer VA; U.S. Preventive Services Task Force: Screening for cervical cancer: U.S. Preventive Services Task Force recommendation statement. Ann Intern Med 156: 880-891, W312, 2012.

34. Botha MH and Dochez C: Introducing human papillomavirus vaccines into the health system in South Africa. Vaccine 30 (Suppl 3): C28-C34, 2012.

35. South African National Cancer Registry: Cancer in South Africa 2014. Johannesburg, 2014. https://www.nicd.ac.za/wp-content/ uploads/2019/12/2014-NCR-tables.pdf. Accessed January 7, 2019.

36. Denny L: Cervical cancer: The South African perspective. FIGO 26th annual report on the results of treatment in gynecological cancer. Int J Gynaecol Obstet 95 (Suppl 1): S211-S214, 2006.

37. Bekker LG, Venter F, Cohen K, Goemare E, Van Cutsem G, Boulle A and Wood R: Provision of antiretroviral therapy in South Africa: The nuts and bolts. Antivir Ther 19 (Suppl 3): S105-S116, 2014

38. Dreyer G: Clinical implications of the interaction between HPV and HIV infections. Best Pract Res Clin Obstet Gynaecol 47: 95-106, 2018

39. Mbulawa ZZA, Coetzee D and Williamson AL: Human papillomavirus prevalence in South African women and men according to age and human immunodeficiency virus status. BMC Infect Dis 15: 459-459, 2015

40. Tathiah N, Naidoo M and Moodley I: Human papillomavirus (HPV) vaccination of adolescents in the South African private health sector: Lessons from the HPV demonstration project in KwaZulu-Natal. S Afr Med J 105: 954, 2015.

41. Lovgren K, Soliman AS, Ngoma T, Kahesa C and Meza J: Characteristics and geographic distribution of HIV-positive women diagnosed with cervical cancer in Dar es Salaam, Tanzania. Int J STD AIDS 27: 1049-1056, 2016.

42. McCree R, Giattas MR, Sahasrabuddhe VV, Jolly PE, Martin MY, Usdan SL, Kohler C and Lisovicz N: Expanding cervical cancer screening and treatment in Tanzania: Stakeholders' perceptions of structural influences on scale-up. Oncologist 20: 621-626, 2015.

43. Ardahan M and Temel AB: Visual inspection with acetic acid in cervical cancer screening. Cancer Nursing 34: 158-163, 2011.

44. Gross K, Armstrong Schellenberg J, Kessy F, Pfeiffer C and Obrist B: Antenatal care in practice: An exploratory study in antenatal care clinics in the Kilombero Valley, south-eastern Tanzania. BMC Pregnancy Childbirth 11: 36, 2011.

45. Runge AS, Bernstein ME, Lucas AN and Tewari KS: Cervical cancer in Tanzania: A systematic review of current challenges in six domains. Gynecol Oncol Rep 29: 40-47, 2019.

46. Mishra GA, Pimple SA and Shastri SS: Prevention of cervix cancer in India. Oncology 91 (Suppl 1): S1-S7, 2016.

47. Senapathy JG, Umadevi P and Kannika PS: The present scenario of cervical cancer control and HPV epidemiology in India: An outline. Asian Pac J Cancer Prev 12: 1107-1115, 2011.

48. Gheit T, Vaccarella S, Schmitt M, Pawlita M, Franceschi S, Sankaranarayanan R, Sylla BS, Tommasino M and Gangane N Prevalence of human papillomavirus types in cervical and oral cancers in central India. Vaccine 27: 636-639, 2009

49. Deodhar K, Gheit T, Vaccarella S, Romao CC, Tenet V, Nene BM, Jayant K, Kelkar R, Malvi SG, Sylla BS, et al: Prevalence of human papillomavirus types in cervical lesions from women in rural Western India. J Med Virol 84: 1054-1060, 2012.

50. Chatterjee S, Chattopadhyay A, Samanta L and Panigrahi P. HPV and cervical cancer epidemiology-current status of HPV vaccination in India. Asian Pac J Cancer Prev 17: 3663-3673, 2016.

51. Mattheij I, Pollock AM and Brhlikova P: Do cervical cancer data justify HPV vaccination in India? Epidemiological data sources and comprehensiveness. J R Soc Med 105: 250-262, 2012.

52. Lopez MS, Baker ES, Maza M, Fontes-Cintra G, Lopez A, Carvajal JM, Nozar F, Fiol V and Schmeler KM: Cervical cancer prevention and treatment in Latin America. J Surg Oncol 115: 615-618, 2017
53. HPV information centre: Brazil human papillomavirus and related cancers, fact sheet 2018 ICO/IARC information centre on HPV and cancer, 2018. https://hpvcentre.net/statistics/reports/ BRA_FS.pdf. Accessed April 17, 2019.

54. Napa LI: Cervical Cancer Screening: Awareness and knowledge in Brazil. Clin Social Work Health Intervention: 55-61, 2016.

55. Lorenzi AT, Syrjänen KJ and Longatto-Filho A: Human papillomavirus (HPV) screening and cervical cancer burden. A Brazilian perspective. Virol J 12: 112-112, 2015.

56. Cohen PA, Jhingran A, Oaknin A and Denny L: Cervical cancer. Lancet 393: 169-182, 2019.

57. Castellsagué X and Muñoz N: Chapter 3: Cofactors in human papillomavirus carcinogenesis-role of parity, oral contraceptives, and tobacco smoking. J Natl Cancer Inst Monogr: 20-28, 2003

58. Chatzistamatiou K, Katsamagas T, Zafrakas M, Zachou K, Orologa A, Fitsiou F, Theodoridis T, Konstantinidis T, Konstantinidis TC and Agorastos T: Smoking and genital human papilloma virus infection in women attending cervical cancer screening in Greece. World J Obstet Gynecol 2: 53-61, 2013.

59. Pista A, de Oliveira CF, Cunha MJ, Paixao MT and Real O; CLEOPATRE Portugal Study Group: Risk factors for human papillomavirus infection among women in Portugal: The CLEOPATRE Portugal Study. Int J Gynaecol Obstet 118 112-116, 2012.

60. International Collaboration of Epidemiological Studies of Cervical Cancer: Comparison of risk factors for invasive squamous cell carcinoma and adenocarcinoma of the cervix: Collaborative reanalysis of individual data on 8,097 women with squamous cell carcinoma and 1,374 women with adenocarcinoma from 12 epidemiological studies. Int J Cancer 120: 885-891, 2007.

61. International Collaboration of Epidemiological Studies of Cervical Cancer, Appleby P, Beral V, Berrington de González A, Colin D, Franceschi S, Goodhill A, Green J, Peto J, Plummer M and Sweetland S: Cervical cancer and hormonal contraceptives: Collaborative reanalysis of individual data for 16,573 women with cervical cancer and 35,509 women without cervical cancer from 24 epidemiological studies. Lancet 370: 1609-1621, 2007.

62. Haverkos HW: Multifactorial etiology of cervical cancer: A hypothesis. MedGenMed 7: 57, 2005.

63. Haverkos HW, Haverkos GP and O'Mara M: Co-carcinogenesis: Human papillomaviruses, coal tar derivatives, and squamous cell cervical cancer. Front Microbiol 8: 2253, 2017.

64. Muñoz N, Castellsagué X, de González AB and Gissmann L: HPV in the etiology of human cancer. Vaccine 24 (Suppl 3): S1-S10, 2006

65. Goodson WH III, Lowe L, Carpenter DO, Gilbertson M, Manaf Ali A, Lopez de Cerain Salsamendi A, Lasfar A, Carnero A, Azqueta A, Amedei A, et al: Assessing the carcinogenic potential of low-dose exposures to chemical mixtures in the environment: The challenge ahead. Carcinogenesis 36 (Suppl 1): S254-S296, 2015.

66. Velema JP, Ferrera A, Figueroa M, Bulnes R, Toro LA, de Barahona O, Claros JM and Melchers WJ: Burning wood in the kitchen increases the risk of cervical neoplasia in HPV-infected women in Honduras. Int J Cancer 97: 536-541, 2002.

67. Bennett C, Kuhn AE and Haverkos HW: Human papillomavirus and tar hypothesis for squamous cell cervical cancer. J Biosci 35: 331-337, 2010.

68. Fujiki H: Gist of Dr. Katsusaburo Yamagiwa's papers entitled 'Experimental study on the pathogenesis of epithelial tumors' (I to VI reports). Cancer Sci 105: 143-149, 2014

69. Rotkin ID: Epidemiology of cancer of the cervix. 3. Sexual characteristics of a cervical cancer population. Am J Public Health Nations Health 57: 815-829, 1967.

70. Karki R, Pandya D, Elston RC and Ferlini C: Defining 'mutation' and 'polymorphism' in the era of personal genomics. BMC Med Genomics 8: 37-37, 2015.

71. Mehta AM, Mooij M, Brankovic I, Ouburg S, Morre SA and Jordanova ES: Cervical carcinogenesis and immune response gene polymorphisms: A review. J Immunol Res 2017: 8913860, 2017.

72. Wang Y and Luo T: LINC00673 rs11655237 polymorphism is associated with increased risk of cervical cancer in a Chinese population. Cancer Control 25: 1073274818803942, 2018.

73. Lu W, Zhang H, Niu Y, Wu Y, Sun W, Li H, Kong J, Ding K, Shen HM, Wu H, et al: Long non-coding RNA linc00673 regulated non-small cell lung cancer proliferation, migration, invasion and epithelial mesenchymal transition by sponging miR-150-5p. Mol Cancer 16: 118, 2017. 
74. Zheng J, Huang X, Tan W, Yu D, Du Z, Chang J, Wei L, Han Y, Wang C, Che X, et al: Pancreatic cancer risk variant in LINC00673 creates a miR-1231 binding site and interferes with PTPN11 degradation. Nat Genet 48: 747-757, 2016.

75. Weng SL, Wu WJ, Hsiao YH, Yang SF, Hsu CF and Wang PH: Significant association of long non-coding RNAs HOTAIR genetic polymorphisms with cancer recurrence and patient survival in patients with uterine cervical cancer. Int $\mathbf{J}$ Med Sci 15: 1312-1319, 2018

76. Pan W, Liu L, Wei J, Ge Y, Zhang J, Chen H, Zhou L, Yuan Q, Zhou C and Yang M: A functional lncRNA HOTAIR genetic variant contributes to gastric cancer susceptibility. Mol Carcinog 55: 90-96, 2016.

77. Chu H, Chen Y, Yuan Q, Hua Q, Zhang X, Wang M, Tong N, Zhang W, Chen J and Zhang Z: The HOTAIR, PRNCR1 and POLR2E polymorphisms are associated with cancer risk: A meta-analysis. Oncotarget 8: 43271-43283, 2017.

78. Yang Y, Liu Y, Li G, Li L, Geng P and Song H: microRNA-214 suppresses the growth of cervical cancer cells by targeting EZH2. Oncol Lett 16: 5679-5686, 2018.

79. Pandey NO, Chauhan AV, Raithatha NS, Patel PK, Khandelwal R Desai AN, Choxi Y, Kapadia RS and Jain ND: Association of TLR4 and TLR9 polymorphisms and haplotypes with cervical cancer susceptibility. Sci Rep 9: 9729-9729, 2019.

80. Fehri E, Ennaifer E, Ardhaoui M, Ouerhani K, Laassili T, Bel Haj Rhouma R, Guizani I and Boubaker S: Expression of Toll-like receptor 9 increases with progression of cervical neoplasia in Tunisian women-a comparative analysis of condyloma, cervical intraepithelial neoplasia and invasive carcinoma. Asian Pac J Cancer Prev 15: 6145-6150, 2014

81. Stamm S, Ben-Ari S, Rafalska I, Tang Y, Zhang Z, Toiber D, Thanaraj TA and Soreq H: Function of alternative splicing. Gene 344: 1-20, 2005.

82. Chen M and Manley JL: Mechanisms of alternative splicing regulation: Insights from molecular and genomics approaches. Nat Rev Mol Cell Biol 10: 741-754, 2009.

83. Tazi J, Bakkour N and Stamm S: Alternative splicing and disease. Biochim Biophys Acta 1792: 14-26, 2009.

84. Gonçalves V, Pereira JFS and Jordan P: Signaling pathways driving aberrant splicing in cancer cells. Genes (Basel) 9: E9, 2017.

85. Irimia $\mathrm{M}$ and Roy SW: Origin of spliceosomal introns and alternative splicing. Cold Spring Harb Perspect Biol 6: a016071, 2014

86. Skotheim RI and Nees M: Alternative splicing in cancer: Noise, functional, or systematic? Int J Biochem Cell Biol 39: 1432-1449, 2007.

87. Faustino NA and Cooper TA: Pre-mRNA splicing and human disease. Genes Dev 17: 419-437, 2003.

88. Bisognin A, Pizzini S, Perilli L, Esposito G, Mocellin S, Nitti D, Zanovello P, Bortoluzzi S and Mandruzzato S: An integrative framework identifies alternative splicing events in colorectal cancer development. Mol Oncol 8: 129-141, 2014.

89. Pal S, Gupta R and Davuluri RV: Alternative transcription and alternative splicing in cancer. Pharmacol Ther 136: 283-294, 2012

90. Chen X, Du H, Liu B, Zou L, Chen W, Yang Y, Zhu Y, Gong Y, Tian J, Li F and Zhong S: The associations between RNA splicing complex gene SF3A1 polymorphisms and colorectal cancer risk in a Chinese population. PLoS One 10: e0130377, 2015.

91. Tian J, Liu Y, Zhu B, Tian Y, Zhong R, Chen W, Lu X, Zou L, Shen N, Qian J, et al: SF3A1 and pancreatic cancer: New evidence for the association of the spliceosome and cancer. Oncotarget 6: 37750-37757, 2015.

92. Yoshida K, Sanada M, Shiraishi Y, Nowak D, Nagata Y, Yamamoto R, Sato Y, Sato-Otsubo A, Kon A, Nagasaki M, et al: Frequent pathway mutations of splicing machinery in myelodysplasia. Nature 478: 64-69, 2011.

93. Liu F, Dai M, Xu Q, Zhu X, Zhou Y, Jiang S, Wang Y, Ai Z, Ma L, Zhang Y, et al: SRSF10-mediated IL1RAP alternative splicing regulates cervical cancer oncogenesis via mIL1RAP-NF-кB-CD47 axis. Oncogene 37: 2394-2409, 2018.

94.Liu B, Tian Y, Li F, Zhao Z, Jiang X, Zhai C, Han X and Zhang L: Tumor-suppressing roles of miR-214 and miR-218 in breast cancer. Oncol Rep 35: 3178-3184, 2016.

95. Korneev KV, Atretkhany KN, Drutskaya MS, Grivennikov SI, Kuprash DV and Nedospasov SA: TLR-signaling and proinflammatory cytokines as drivers of tumorigenesis. Cytokine 89: $127-135,2017$.

96.Zidi S,Sghaier I,GazouaniE, Mezlini A and Yacoubi-Loueslati B: Evaluation of Toll-Like receptors $2 / 3 / 4 / 9$ gene polymorphisms in cervical cancer evolution. Pathol Oncol Res 22: 323-330, 2016.
97. Yang X, Cheng Y and Li C: The role of TLRs in cervical cancer with HPV infection: A review. Signal Transduct Target Ther 2: $17055,2017$.

98. Urban-Wojciuk Z, Khan MM, Oyler BL, Fåhraeus R, Marek-Trzonkowska N, Nita-Lazar A, Hupp TR and Goodlett DR: The role of TLRs in anti-cancer immunity and tumor rejection. Front Immunol 10: 2388, 2019.

99. Zhou Q, Zhu K and Cheng H: Toll-like receptors in human papillomavirus infection. Arch Immunol Ther Exp (Warsz) 61: 203-215, 2013

100. Hasimu A, Ge L, Li QZ, Zhang RP and Guo X: Expressions of Toll-like receptors $3,4,7$, and 9 in cervical lesions and their correlation with HPV16 infection in Uighur women. Chin J Cancer 30: 344-350, 2011.

101. DeCarlo CA, Rosa B, Jackson R, Niccoli S, Escott NG and Zehbe I: Toll-like receptor transcriptome in the HPV-positive cervical cancer microenvironment. Clin Dev Immunol 2012: 785825,2012

102. Daud II, Scott ME, Ma Y, Shiboski S, Farhat S and Moscicki AB: Association between toll-like receptor expression and human papillomavirus type 16 persistence. Int J Cancer 128: 879-886, 2011

103. Hasan UA, Bates E, Takeshita F, Biliato A, Accardi R, Bouvard V, Mansour M, Vincent I, Gissmann L, Iftner T, et al: TLR9 expression and function is abolished by the cervical cancer-associated human papillomavirus type 16. J Immunol 178: 3186-3197, 2007.

104.Hasan UA, Zannetti C, Parroche P, Goutagny N, Malfroy M, Roblot G, Carreira C, Hussain I, Müller M, Taylor-Papadimitriou J, et al: The human papillomavirus type 16 E7 oncoprotein induces a transcriptional repressor complex on the Toll-like receptor 9 promoter. J Exp Med 210: 1369-1387, 2013.

105. Zolini GP, Lima GK, Lucinda N, Silva MA, Dias MF, Pessoa NL, Coura BP, Cartelle CT, Arantes RM, Kroon EG and Campos MA: Defense against HSV-1 in a murine model is mediated by iNOS and orchestrated by the activation of TLR 2 and TLR9 in trigeminal ganglia. J Neuroinflammation 11: 20, 2014.

106. Parroche P, Roblot G, Le Calvez-Kelm F, Tout I, Marotel M, Malfroy M, Durand G, McKay J, Ainouze M, Carreira C, et al: TLR9 re-expression in cancer cells extends the S-phase and stabilizes p16(INK4a) protein expression. Oncogenesis 5: e244, 2016.

107. Kaur G and Sethi RS: Multiple exposures to poultry barn air and lipopolysaccharide synergistically increase the pulmonary expression of TLR-4 and IL-1 $\beta$. J Occup Health: Oct 27, 2019 (Epub ahead of print). doi: 10.1002/1348-9585.12094.

108. Felekkis K, Touvana E, Stefanou C and Deltas C: microRNAs: A newly described class of encoded molecules that play a role in health and disease. Hippokratia 14: 236-240, 2010.

109. Calin GA, Dumitru CD, Shimizu M, Bichi R, Zupo S, Noch E, Aldler H, Rattan S, Keating M, Rai K, et al: Frequent deletions and down-regulation of micro- RNA genes miR15 and miR16 at 13 q14 in chronic lymphocytic leukemia. Proc Natl Acad Sci USA 99: 15524-15529, 2002

110. Deng Y, Xiong Y and Liu Y: miR-376c inhibits cervical cancer cell proliferation and invasion by targeting BMI1. Int J Exp Pathol 97: 257-265, 2016.

111. Zhang B, Pan X, Cobb GP and Anderson TA: microRNAs as oncogenes and tumor suppressors. Dev Biol 302: 1-12, 2007.

112. Fan Z, Cui H, Yu H, Ji Q, Kang L, Han B, Wang J, Dong Q, Li Y, Yan Z, et al: MiR-125a promotes paclitaxel sensitivity in cervical cancer through altering STAT3 expression. Oncogenesis 5: e223, 2016.

113. Fang W, Shu S, Yongmei L, Endong Z, Lirong Y and Bei S: miR-224-3p inhibits autophagy in cervical cancer cells by targeting FIP200. Sci Rep 6: 33229, 2016.

114. Huang P, Xi J and Liu S: MiR-139-3p induces cell apoptosis and inhibits metastasis of cervical cancer by targeting NOB1. Biomed Pharmacother 83: 850-856, 2016.

115. Cheng X, Chen J and Huang Z: miR-372 promotes breast cancer cell proliferation by directly targeting LATS2. Exp Ther Med 15: 2812-2817, 2018

116. Liao J, Lin J, Lin D, Zou C, Kurata J, Lin R, He Z and Su Y: Down-regulation of miR-214 reverses erlotinib resistance in non-small-cell lung cancer through up-regulating LHX6 expression. Sci Rep 7: 781, 2017.

117. Lu Q, Xu L, Li C, Yuan Y, Huang S and Chen H: miR-214 inhibits invasion and migration via downregulating GALNT7 in esophageal squamous cell cancer. Tumour Biol 37: 14605-14614, 2016. 
118. Xia D, Li X, Niu Q, Liu X, Xu W, Ma C, Gu H, Liu Z, Shi L, Tian X, et al: MicroRNA-185 suppresses pancreatic cell proliferation by targeting transcriptional coactivator with PDZ-binding motif in pancreatic cancer. Exp Ther Med 15: 657-666, 2018.

119. Yu G, Wang J, Xu K and Dong J: Dynamic regulation of uncoupling protein 2 expression by microRNA-214 in hepatocellular carcinoma. Biosci Rep 36: e00335, 2016.

120.Zhu X, Ju S, Yuan F, Chen G, Shu Y, Li C, Xu Y, Luo J and Xia L: microRNA-664 enhances proliferation, migration and invasion of lung cancer cells. Exp Ther Med 13: 3555-3562, 2017.

121. Chen Z, Wang M, He Q, Li Z, Zhao Y, Wang W, Ma J, Li Y and Chang G: MicroRNA-98 rescues proliferation and alleviates ox-LDL-induced apoptosis in HUVECs by targeting LOX-1. Exp Ther Med 13: 1702-1710, 2017.

122.Zhu Y, Wu G, Yan W, Zhan H and Sun P: miR-146b-5p regulates cell growth, invasion, and metabolism by targeting PDHB in colorectal cancer. Am J Cancer Res 7: 1136-1150, 2017.

123.Dong J, Wang M, Ni D, Zhang L, Wang W, Cui X, Fu S and Yao S: MicroRNA-217 functions as a tumor suppressor in cervical cancer cells through targeting Rho-associated protein kinase 1. Oncoly Lett 16: 5535-5542, 2018.

124. Scarinci IC, Garcia FAR, Kobetz E, Partridge EE, Brandt HM, Bell MC, Dignan M, Ma GX, Daye JL and Castle PE: Cervical cancer prevention: New tools and old barriers. Cancer 116 2531-2542, 2010.

125. Adesina A, Chumba D, Nelson AM, Orem J, Roberts DJ, Wabinga $\mathrm{H}$, Wilson $\mathrm{M}$ and Rebbeck TR: Improvement of pathology in sub-Saharan Africa. Lancet Oncol 14: e152-e157, 2013.

126. Gelband H, Sankaranarayanan R, Gauvreau CL, Horton S, Anderson BO, Bray F, Cleary J, Dare AJ, Denny L, Gospodarowicz MK, et al: Costs, affordability, and feasibility of an essential package of cancer control interventions in low-income and middle-income countries: Key messages from Disease Control Priorities, 3rd edition. Lancet 387: 2133-2144, 2016.

127. Goss PE, Lee BL, Badovinac-Crnjevic T, Strasser-Weippl K, Chavarri-Guerra Y, St Lou is J, Villarreal-Garza C, Unger-Saldaña K, Ferreyra M, Debiasi M, et al: Planning cancer control in Latin America and the Caribbean. Lancet Oncol 14 391-436, 2013

128. Jit M, Brisson M,Portnoy A and Hutubessy R: Cost-effectiveness of female human papillomavirus vaccination in 179 countries: A PRIME modelling study. Lancet Glob Health 2: e406-e414, 2014.

129. Schiller JT, Castellsagué X and Garland SM: A review of clinical trials of human papillomavirus prophylactic vaccines. Vaccine 30: F123-F138, 2012.

130.FUTURE II Study Group: Quadrivalent vaccine against human papillomavirus to prevent high-grade cervical lesions. N Engl J Med 356: 1915-1927, 2007.

131. Joura EA, Giuliano AR, Iversen OE, Bouchard C Mao C, Mehlsen J, Moreira ED Jr, Ngan Y, Petersen LK, Lazcano-Ponce E, et al: A 9-valent HPV vaccine against infection and intraepithelial neoplasia in women. N Engl J Med 372: 711-723, 2015.

132.Levin A, Wang SA, Levin C, Tsu V and Hutubessy R: Costs of introducing and delivering HPV vaccines in low and lower middle income countries: Inputs for GAVI policy on introduction grant support to countries. PLoS One 9: e101114, 2014.
133. Goldie SJ, Gaffikin L, Goldhaber-Fiebert JD, Gordillo-Tobar A Levin C, Mahé C and Wright TC; Alliance for Cervical Cancer Prevention Cost Working Group: Cost-effectiveness of cervical-cancer screening in five developing countries. N Engl J Med 353: 2158-2168, 2005.

134. Cronjé HS and Beyer E: Screening for cervical cancer in an African setting. Int J Gynaecol Obstet 98: 168-171, 2007.

135. Gakidou E, Nordhagen S and Obermeyer Z: Coverage of cervical cancer screening in 57 countries: Low average levels and large inequalities. PLoS Med 5: e132, 2008.

136. Wake RM, Rebe K and Burch VC: Patient perception of cervical screening among women living with human immuno-deficiency virus infection attending an antiretroviral therapy clinic in urban South Africa. J Obstet Gynaecol 29: 44-48, 2009.

137. Gopal S, Achenbach CJ, Yanik EL, Dittmer DP, Eron JJ and Engels EA: Moving forward in HIV-associated cancer. J Clin Oncol 32: 876-880, 2014

138. Bruggmann D, Kayser L, Jaque J, Bundschuh M, Klingelhöfer D and Groneberg DA: Human papilloma virus: Global research architecture assessed by density-equalizing mapping. Oncotarget 9: 21965-21977, 2018.

139. Ndejjo R, Mukama T, Musabyimana A and Musoke D: Uptake of cervical cancer screening and associated factors among women in Rural Uganda: A cross sectional study. PLoS One 11: $\mathrm{e} 0149696,2016$.

140. Idehen EE, Korhonen T, Castaneda A, Juntunen T, Kangasniemi M, Pietilä AM and Koponen P: Factors associated with cervical cancer screening participation among immigrants of Russian, Somali and Kurdish origin: A population-based study in Finland. BMC Women Health 17: 19, 2017.

141. Marlow LA, Wardle J and Waller J: Understanding cervical screening non-attendance among ethnic minority women in England. Br J Cancer 113: 833-839, 2015.

142.Olsson E, Lau M, Lifvergren S and Chakhunashvili A: Community collaboration to increase foreign-born women's participation in a cervical cancer screening program in Sweden: A quality improvement project. Int J Equity Health 13: 62, 2014.

143. Raine R, Fitzpatrick R, Barratt H, Bevan G, Black N, Boaden R, Bower P, Campbell M, Denis JL, Devers K, et al: Challenges, solutions and future directions in the evaluation of service innovations in health care and public health. Health Services and Delivery Researc 4: 16, 2016.

144. Karl-Trummer U and Sardadvar S: The interplay of health, migrant status and socioeconomic status in eight EU countries. Health inequalities and risk factors among migrants and ethnic minorities. COST Series Health Div 1: 79-92, 2012.

145. Simon J, Kiss N, Łaszewska A and Mayer S: Public health aspects of migrant health: a review of the evidence on health status for labour migrants in the European Region. World Health Organisation Regional Office for Europe 2015.

146. Kunckler M, Schumacher F, Kenfack B, Catarino R, Viviano M, Tincho E, Tebeu PM, Temogne L, Vassilakos P and Petignat P: Cervical cancer screening in a low-resource setting: A pilot study on an HPV-based screen-and-treat approach. Cancer Med 6: 1752-1761, 2017.

This work is licensed under a Creative Commons Attribution-NonCommercial-NoDerivatives 4.0 International (CC BY-NC-ND 4.0) License. 